\title{
Development and Validation of a Battery of Emotionally Evocative Film Clips for Use with Young Children
}

Lindsay Gabel, The University of Western Ontario

Supervisor: Hayden, Elizabeth P., The University of Western Ontario

A thesis submitted in partial fulfillment of the requirements for the Master of Science degree in Psychology

(C) Lindsay Gabel 2019

Follow this and additional works at: https://ir.lib.uwo.ca/etd

Part of the Developmental Psychology Commons

\section{Recommended Citation}

Gabel, Lindsay, "Development and Validation of a Battery of Emotionally Evocative Film Clips for Use with Young Children" (2019). Electronic Thesis and Dissertation Repository. 6491.

https://ir.lib.uwo.ca/etd/6491

This Dissertation/Thesis is brought to you for free and open access by Scholarship@Western. It has been accepted for inclusion in Electronic Thesis and Dissertation Repository by an authorized administrator of Scholarship@Western. For more information, please contact wlswadmin@uwo.ca. 


\title{
EMOTION-ELICITING FILM CLIPS FOR CHILDREN
}

\begin{abstract}
Investigating normative and maladaptive emotional development requires the ability to elicit children's reactivity to a range of affective stimuli. However, the field lacks a validated battery of stimuli tapping a broad range of childhood emotions. We therefore sought to validate a developmentally appropriate battery of emotionally evocative film stimuli, covering a range of affective responses, for use with children. During pilot work, clips were verified as age-appropriate by parents of young children. Next, during a laboratory visit, 39 children $\left(22\right.$ girls; $M_{\text {age }}=7.19$ years, $\left.S D=.76\right)$ viewed 20 film clips thought likely to elicit either positive affect, dysphoria (i.e., sadness/anger), or fear, and provided self-reported emotional responses to clips. Children's facial expressions during clips were also rated by trained coders blind to the intended purpose of the clips. We identified clips that successfully elicited the target emotion more so than nontarget emotions according to both coder ratings and child self-report. Associations between reactivity to the clips and child age and sex were limited. Several significant, meaningful associations between reactivity to clips and caregiver-reported child emotion regulation were found. Implications for the use of these film clips in future research on child emotion are discussed.
\end{abstract}

Keywords: mood induction, emotion, childhood, film clips 


\section{EMOTION-ELICITING FILM CLIPS FOR CHILDREN}

\section{Co-Authorship Statement}

The following people and institutions contributed to the publication of work undertaken as part of this thesis:

Lindsay N. Gabel, Department of Psychology, Brain and Mind Institute, Western University (Master's Candidate), was the primary author and was responsible for the analysis and interpretation of research data and preparation of the manuscript.

Andrew R. Daoust and Marlee R. Salisbury, Department of Psychology, Brain and Mind Institute, Western University, assisted with data collection.

Jessica A. Grahn, Department of Psychology, Brain and Mind Institute, Western University and C. Emily Durbin, Department of Psychology, Michigan State University, contributed to the conceptualization and design of the study.

Elizabeth P. Hayden, Department of Psychology, Brain and Mind Institute, Western University, was the Principal Investigator and led the conceptualization and design of the study, grant-writing, and assisted in data analysis and interpretation of the results. 


\section{EMOTION-ELICITING FILM CLIPS FOR CHILDREN}

\section{Acknowledgements}

First and foremost, I wish to thank my supervisor, Dr. Elizabeth Hayden, who made this work possible. Thank you for your unwavering support, expert guidance, and sense of humour throughout this process. I could not have asked for a better mentor. To the members of the Hayden Lab, it is without question that thesis-writing — and indeed my entire graduate school experience - has been made infinitely better because of you. Thank you is not enough.

I express my appreciation to my co-authors of the publication on which my thesis is based, as well as our two reviewers, for their valuable contributions and insights. My thesis has benefited greatly from your time and perspective and for that I am very grateful. Thank you also to my thesis committee, Drs. Lindsay Bodell, Alan Leschied, and John Paul Minda, for their time and expertise.

I extend my gratitude to the participants and their families, who so generously and enthusiastically donated their time to this project. I also thank the Natural Sciences and Engineering Research Council of Canada (NSERC) and the Children's Health Research Institute (CHRI) for providing the financial support that I hope will in turn, through this work, benefit others seeking to advance the child emotion literature.

Lastly, I wish to thank my family and partner. To my parents, thank you for all that you have given me that has allowed me to be where I am. To my sisters, Candace and Haley, thank you for supporting me in anything and everything. And to Tyler, thank you for your endless patience, encouragement, and for laughing at my research jokes even when they are not funny. 


\section{EMOTION-ELICITING FILM CLIPS FOR CHILDREN}

\section{Table of Contents}

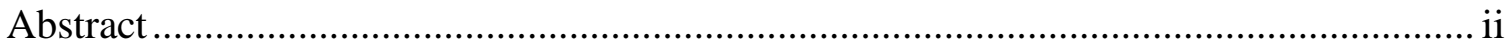

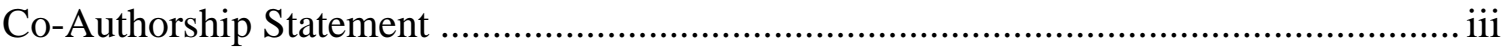

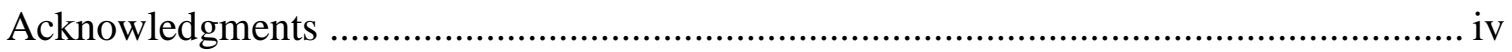

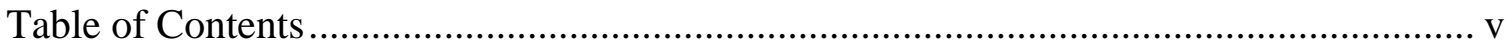

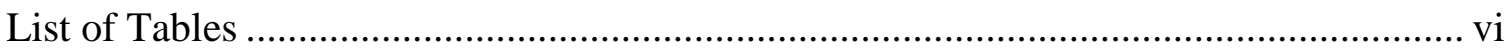

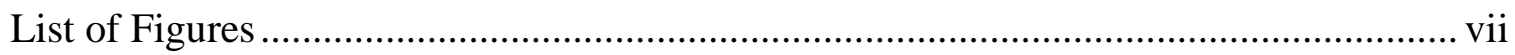

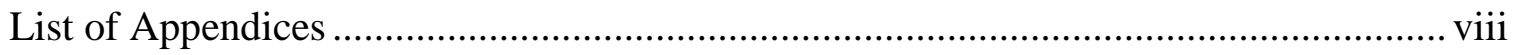

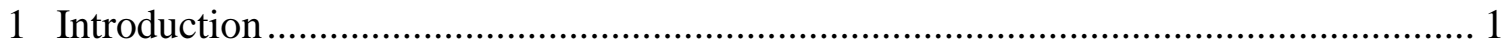

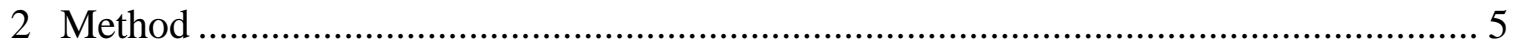

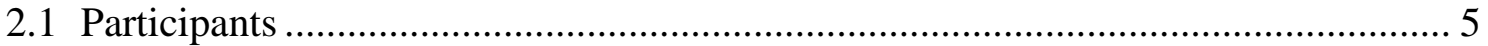

2.2 Selection of Emotionally Evocative Film Clips ............................................... 6

2.3 Measures ................................................................................................ 7

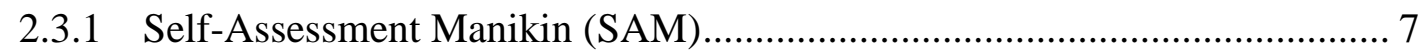

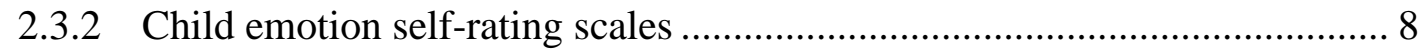

2.3.3 Emotion Regulation Checklist (ERC) ................................................ 8

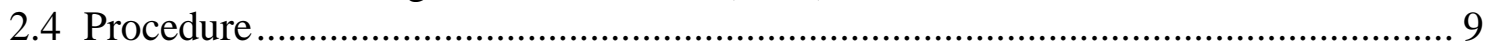

2.5 Child Emotion Coding................................................................................ 11

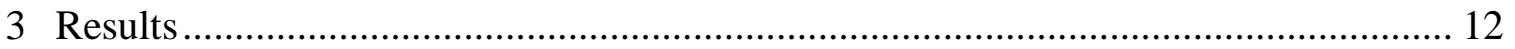

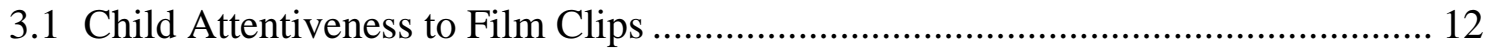

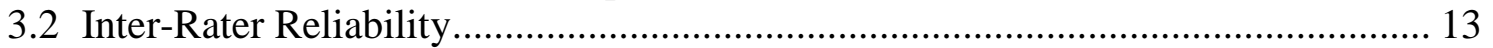

3.3 Within-Clip Comparisons of Target to Non-Target Emotions............................. 13

3.4 Clip Valence and Arousal............................................................................. 15

3.5 Associations Between Age and Emotional Responses to Clips ............................. 16

3.6 Exploratory Analyses of Sex Differences in Target Emotional Responses ............ 16

3.7 Associations Between ERC Subscales and Target Emotional Responses .............. 18

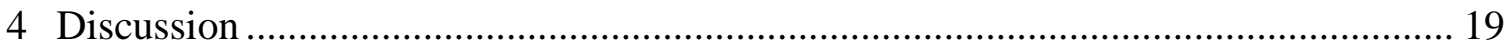

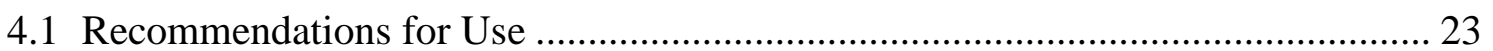

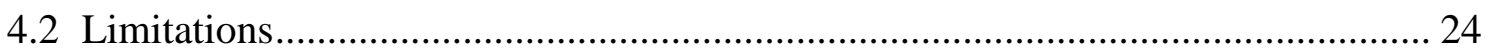

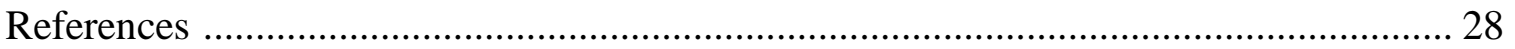

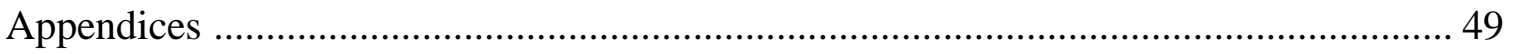

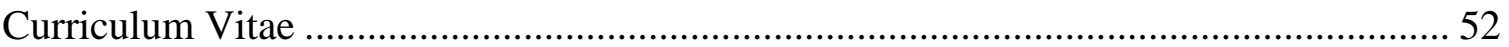




\section{EMOTION-ELICITING FILM CLIPS FOR CHILDREN}

\section{List of Tables}

Table 1: Final battery of 20 film clips shown to children during laboratory sessions .......37

Table 2: Clips intended to evoke positive affect: Descriptive statistics and paired $t$-tests comparing positive affect to sadness, fear, and anger using coder ratings of emotional response and child self-reported emotion

Table 3: Clips intended to evoke dysphoria (i.e., sadness and/or anger): Descriptive statistics and paired $t$-tests comparing sadness to positive affect, fear, and anger using coder ratings of emotional response and child self-reported emotion

Table 4: Clips intended to evoke fear: Descriptive statistics and paired $t$-tests comparing fear to positive affect, sadness, and anger using coder ratings of emotional response and child self-reported emotion

Table 5: Correlations between child age, coder-rated positive affect, child-reported positive affect, child attentiveness, and ERC subscales for clips intended to evoke positive affect

Table 6: Correlations between child age, coder-rated sadness, child-reported sadness, child attentiveness, and ERC subscales for clips intended to evoke dysphoria (i.e., sadness and/or anger)

Table 7: Correlations between child age, coder-rated fear, child-reported fear, child attentiveness, and ERC subscales for clips intended to evoke fear 46

Table 8: Exploratory independent samples $t$-tests of sex differences in targeted emotional response, child attentiveness, and SAM valence and arousal according to coder and child ratings. 


\section{EMOTION-ELICITING FILM CLIPS FOR CHILDREN}

\section{List of Figures}

Figure 1: The child emotion self-rating scales for positive affect, sadness, fear, and

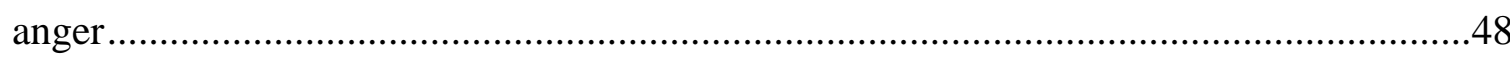




\section{EMOTION-ELICITING FILM CLIPS FOR CHILDREN}

\section{List of Appendices}

Appendix A: Protocol for Introducing and Collecting Child-Reported Emotion and SAM

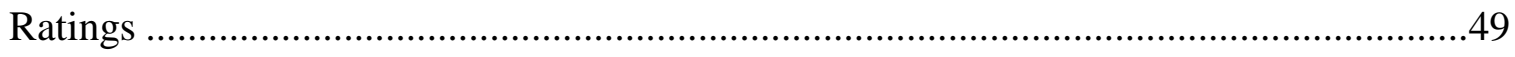

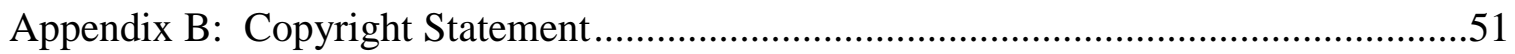


Development and Validation of a Battery of Emotionally Evocative Film Clips for Use with Young Children

The expression and regulation of emotion play a significant role in both successful and maladaptive development (Gross, 2013). Negative emotions, for instance, allow one to survive and thrive in the face of environmental threat by signalling the need to escape, attack, or expel (Fredrickson, 2004). Positive emotions are adaptive in that they broaden one's repertoires of thoughts and behaviors in ways that foster creativity, learning, and social connection, thereby building enduring psychological and social resources upon which one can draw in times of struggle (Fredrickson, 2004; Meehl, 1975). Indeed, the experience of both positive and negative emotion is essential for psychological resiliency and wellbeing (Fredrickson, 2004; Meehl, 1975). Conversely, extreme emotional reactivity and difficulties in regulating emotion have been linked to risk for various psychopathologies across the lifespan (Eisenberg, Spinrad, \& Eggum, 2010; Schäfer, Naumann, Holmes, Tuschen-Caffier, \& Samson, 2017; Compas et al., 2017; Aldao, Nolen-Hoeksema, \& Schweizer, 2010; Nolen-Hoeksema, 2012). For these reasons, researchers focused on both normative emotional development and psychopathology have a longstanding interest in understanding early emotion.

Childhood in particular provides an important window for understanding the emergence and maturation of emotion processes. Examining emotional phenomena early in development may speak to the developmental pathways that link these phenomena with later psychological outcomes (Zeman, Klimes-Dougan, Cassano, \& Adrian, 2007). There is thus a pressing need for effective paradigms that elicit emotion in children to facilitate studies of normative and maladaptive emotional development. While the "affect 
revolution" (Fischer \& Tangney, 1995) of the past two decades has seen considerable research on child emotion (Adrian, Zeman, \& Veits, 2011), the enthusiasm with which emotion and its regulation are invoked as mechanisms for key developmental outcomes has outpaced the availability of validated and developmentally sensitive methodological tools for investigating these phenomena across a broad range of emotions. Advances in the measurement of child emotion are therefore critical for the continued progression of the field.

With respect to past work, paradigms designed to induce emotions in the laboratory (i.e., mood induction paradigms; MIPs) have been widely used by the field for some time (Gilman et al., 2017). However, this research, particularly that focused on early childhood, has often proceeded in a piecemeal fashion, with research groups often choosing their own idiosyncratic method of child mood induction. More specifically, a wide range of stimuli, including images, stories, music, experimenter behavior, manipulations of feedback on performance, self-generated mental imagery, and autobiographical recall, have been used to induce mood (Brenner, 2000), without a clear "gold-standard" approach emerging for use with young children.

Nevertheless, extant work indicates that video clips are, in general, an especially effective approach to inducing both positive and negative emotional states (Westermann, Spies, Stahl, \& Hesse, 1996; Zupan \& Babbage, 2017). Indeed, the potentially high potency, ecological validity, and ease of standardization both within and across studies (Hewig et al., 2005; Rottenberg, Ray, \& Gross, 2007), support the notion that video clips are ideal stimuli for eliciting emotions in the laboratory. Video stimuli may be particularly useful for mood induction with children because they transcend certain 
methodological challenges associated with eliciting emotion in this population. For instance, peripheral data collection procedures involved in MIP studies, such as interacting with an unfamiliar experimenter in a novel setting, may inadvertently influence children's emotional states (Henderson \& Fox, 2007) and introduce unwanted variation related to differences in experimenters' behavior. In contrast, MIPs that use video stimuli reduce experimenter involvement and can therefore potentially be administered with greater consistency across participants. Additionally, watching videos is a familiar and engaging activity for most children (von Leupoldt et al., 2007). Further, individual differences in children's developmental status or cognitive ability may introduce unwanted variability in MIPs when stimuli that place significant cognitive demands on children are used, such as those in which children must recall memories or generate mental imagery (Stegge, Meerum Terwogt, \& Koops, 1995). In contrast, MIPs that use video clips place few demands on children's cognitive resources, minimizing the influence of these factors on mood induction efficacy.

Despite clear methodological advantages of using video stimuli to elicit emotions in young children, research validating developmentally sensitive video clips for this population is scarce. While there have been exhaustive efforts to develop and validate emotionally evocative video stimuli for use with adults (Carvalho, Leite, Galdo-Álvarez, \& Gonçalves, 2012; Gilman et al., 2017; Gross \& Levenson, 1995; Hewig et al., 2005; Schaefer, Nils, Sanchez, \& Philippot, 2010), these stimuli do not translate well to younger populations due to the unique phenomenological and ethical issues associated with eliciting emotion in children (Zeman et al., 2007). For instance, video clips that are effective in evoking emotion in adults (such as those catalogued by Gilman et al., 2017) 
may be less engaging for children (e.g., stand-up comedy routines for adult audiences), rely on complex emotional material that may be developmentally incongruent (e.g., romantic love), or contain content parents would find objectionable (e.g., extremely violent or frightening scenes).

While many studies of child emotion have used emotionally evocative stimuli, including film clips (Brenner, 2000), many studies focus on a single emotion of interest (e.g., positive affect; Morrongiello, Stewart, Pope, Pogrebtsova, \& Boulay, 2015) and thorough validation and standardization of such stimuli is often lacking. Without confirmation that stimuli reliably elicit the intended emotions, valid inferences about the emotional phenomena under study are limited. Secondly, most studies of children's emotion development and regulation have used only one method to index children's emotional expression and regulation (e.g., child self-report; Adrian et al., 2011). A multimethod approach to verifying emotional responses to stimuli is, however, critical for validating the efficacy of experimental manipulations (Brenner, 2000; Cole, Martin, \& Dennis, 2004), especially considering the susceptibility of children's self-report to demand characteristics (Brenner, 2000; Zeman et al., 2007). Lastly, hedonic valence is often considered a sufficient measure of children's emotional responses to stimuli (e.g., von Leupoldt et al., 2007). However, given that video clips may elicit a range of emotional responses, including unanticipated or multiple emotions (Rottenberg et al., 2007; Henderson \& Fox, 2007), assessing a range of emotions may yield a more finegrained, nuanced picture of children's emotional experiences (Brenner, 2000).

With this literature in mind, we aimed to compile a developmentally appropriate, validated, and relatively broad battery of emotionally evocative film clips for examining 
children's emotional experience and regulation. In addition, we attempted to address the issues identified above by using multiple methods to assess the discrete emotions elicited by clips. To this end, we assessed children's positive affectivity, dysphoria (i.e., sadness/anger), and fear in response to a battery of film clips using children's self-report as well as coder ratings of children's video-recorded facial expressions.

We also examined associations between children's reactivity to clips and child attentiveness to clips, child age, child sex, and caregiver-reported child emotion regulation. With respect to the first three factors, we aimed to identify clips that were engaging and minimally related to child age and sex. With respect to caregiver-reported child emotion regulation, in exploratory analyses, we sought to examine a potential marker of the ecological validity of the clips by correlating children's reactivity to clips with caregiver perceptions of children's typical emotional tendencies.

\section{Method}

\section{Participants}

Thirty-nine children aged six to eight $(M=7.19$ years, $S D=.76$; girls $N=22)$ were recruited from Southwestern Ontario through outreach to families participating in other studies and advertisements placed in the community. Based on initial screening done by a trained research assistant, children with any medical or psychological condition that would potentially impact their ability to participate were ineligible. The sample was predominantly white $(87.2 \%)$, with the remainder of the sample identifying as multiracial (7.7\%), Hispanic or Latino (2.6\%), or Asian (2.6\%), and middle-class, with $30.8 \%$ reporting an annual family income of more than $\$ 100,000,25.6 \%$ between $\$ 70,001$ and $\$ 100,000,15.4 \%$ between $\$ 40,001$ and $\$ 70,000$, and $7.7 \%$ between $\$ 20,000$ and $\$ 40,000$. 
Information on annual family income was not available for $20.5 \%$ of the sample. The study was approved by the institutional research ethics board and all parents and children were compensated for their participation.

\section{Selection of Emotionally Evocative Film Clips}

Emotionally evocative film clips were sourced from the childhood emotion literature as well as age-appropriate films and television programs identified by our research group. This process yielded 22 video clips selected based on their potential to elicit a strong emotional response and grouped according to three target emotional responses: positive affect, dysphoria (i.e., sadness and anger), and fear. We considered dysphoria and fear as separate target emotions when selecting clips based on evidence suggesting that fear represents a different neurobiological substrate (Vizueta, Patrick, Jiang, Thomas, \& He, 2012) and temperament trait (Dyson, Olino, Durbin, Goldsmith, \& Klein, 2012) from other negative affective states such as sadness and anger. In addition, given evidence that anger and sadness are not well differentiated in younger children (Dyson et al., 2012), we used the broader category of "dysphoria" to group clips intended to elicit sadness and/or anger; however, to allow for a more nuanced picture of children's dysphoric responses, we coded sadness and anger separately.

To confirm that film clips were acceptable for use with child participants, eight parents of children aged six to eight who had participated in previous research studies conducted by our group were asked to view the initial pool of clips and provide feedback. Parents viewed the 22 clips, rated each clip's acceptability, and provided qualitative written feedback regarding the appropriateness of each clip. Based on this feedback, two of the clips selected to elicit fear were dropped from the pool as multiple parents felt 
these clips were overly frightening. The final battery of film clips consisted of 20 clips (see Table 1); we anticipated that six of these would elicit positive affect, seven would elicit dysphoria (i.e., sadness or anger), and seven would elicit fear.

\section{Measures}

Both child self-report and objective emotion coding were used to verify whether the selected film clips elicited the intended emotional response. Coders were blind to the film clips that children were watching and the targeted emotion. Given the importance of using both discrete and dimensional approaches to emotion measurement (Schaefer et al., 2010), two quantitative indices of child-reported emotion were used: the Self-Assessment Manikin (SAM; Bradley \& Lang, 1994) and a set of standardized emotion face icons, hereafter referred to as the "child emotion self-rating scales." In addition, caregiver perceptions of children's emotion regulation were assessed using the Emotion Regulation Checklist (Shields \& Cicchetti, 1997).

Self-Assessment Manikin (SAM; Bradley \& Lang, 1994). The SAM is a widely used pictorial affective rating system that has been validated for use with young children (Greenbaum, Turner, Cook, \& Melamed, 1990; Leventon \& Bauer, 2016). In the SAM, children rate their emotional response to stimuli using two 9-point scales assessing valence $(1=$ very positive, $9=$ very negative $)$ and arousal $(1=$ high arousal, $9=$ low arousal). Illustrations of a humanlike figure (introduced to children as "Sam") showing the range of emotional states accompany the numerical anchors for both scales. A third SAM scale assessing dominance was not of interest in the present study and was not used. 
Child emotion self-rating scales. We developed a set of visual analog scales based on measures used in previous work (Christodoulou \& Burke, 2016; Davis, QuiñonesCamacho, \& Buss, 2016; Goldschmidt, Tanofsky-Kraff, \& Wilfley, 2011; Gotlib, Traill, Montoya, Joormann, \& Chang, 2005; Wong \& Baker, 1988). The inclusion of this second rating system, which assessed the intensity of specific emotions, allowed for more finegrained distinctions in emotional response than the SAM scales. While the SAM and other previously used scales are bipolar in nature (e.g., sadness and happiness at opposing ends), the child emotion self-rating scales were separate unipolar scales for various emotions. Specifically, children self-rated their positive affect, sadness, fear, and anger to each clip using four separate 4-point scales ( $1=$ no emotion, $4=$ highest level of a given emotion). Illustrations of facial icons as well as text indicating the emotion (e.g., "sad") in increasing font size accompanied the numerical anchors for each scale to show the different levels of emotional intensity (Figure 1).

Emotion Regulation Checklist (ERC; Shields \& Cicchetti, 1997). The ERC is a 24-item informant-report measure that assesses emotion regulation in youth aged 6-18. Caregivers report the frequency of children's various emotion-related behaviours using a 4-point Likert scale ( $1=$ "never" to 4 = "almost always"). The ERC is composed of the Emotion Regulation (ER) subscale and Lability/Negativity (LN) subscales. The ER subscale contains 8 items and captures whether children display situationally appropriate affect, empathy, and emotional self-awareness, with higher scores indicating better regulation of emotion. The $\mathrm{LN}$ subscale contains 16 items and captures whether children exhibit emotional inflexibility, dysregulated negative affect, and unpredictable mood change; thus, higher scores indicate greater emotional lability. Psychometric data for the 
ERC provide evidence for its convergent and discriminant validity, as well as the internal consistency of the ER and LN subscales (Shields \& Cicchetti, 1997). Subsequent studies have confirmed the two-factor structure of the ERC and provided further support for the ERC's construct validity (Kim-Spoon, Cicchetti, \& Rogosch, 2013; Miller, Kiely Gouley, Seifer, Dickstein, \& Shields, 2004; Shields \& Cicchetti, 1997).

Consistent with previous work using the ERC, we found relatively good internal consistency for the ER and LN subscales, with Cronbach's alphas of .72 and .84, respectively. Descriptive statistics for our sample for both the ER subscale $(M=3.55, S D$ $=.36$, Range: 1.25 to 2.75$)$ and the $\mathrm{LN}$ subscale $(M=1.69, S D=.39$, Range: 1.13 to 2.63) were also similar to those reported in previous studies using community samples of young children (e.g., Kim-Spoon et al., 2013; Molina et al., 2014).

\section{Procedure}

Each child and a parent were invited to lab sessions in which the child viewed the battery of selected film clips. Parents were informed of the film clips that would be shown to children prior to their lab visit. The order in which the 20 clips were presented was randomized for each child to address order and carryover effects. Sessions took approximately 70 minutes to complete and were conducted one-on-one with a graduatelevel or postbaccalaureate research assistant. Children were seated in the same designated spot in a room with minimal stimuli, facing a large TV screen mounted on a wall.

Research assistants informed children that they would be watching a series of movie clips and asked how each clip made them feel.

Prior to presentation of the first clip, children completed questionnaires with a research assistant to acclimatize them to the laboratory setting and research assistant. The 
research assistant then explained the SAM and child emotion self-rating scales to the child using a standardized script (see Appendix A). The research assistant verified the child's comprehension of both rating systems by asking the child to rate how he or she might feel after watching a movie that made him or her feel sad, using additional examples if necessary. Lastly, children were told that it was possible to feel more than one emotion in response to a clip and were encouraged to endorse multiple emotional responses if needed; thus, all four of the child emotion self-rating scales were administered for each film clip regardless of whether the clip was expected to elicit positive affect, sadness, anger, or fear. We did not collect a baseline mood rating from children given that the order in which film clips were presented was randomized for each child, thus controlling for potential effects of children's baseline mood on their emotional responses to clips.

The first film clip was subsequently presented on the TV screen. Immediately following the clip, the research assistant, using a neutral tone, prompted the child to rate his or her emotional response using the SAM and child emotion self-rating scales. For the child emotion self-rating scales, the child was asked, "How [emotion; e.g., angry] did this movie clip make you feel? Not at all [emotion], a little [emotion], even more [emotion], or very [emotion]?", as the research assistant pointed to the respective anchors. For the SAM valence and arousal scales, the research assistant reminded the child of the anchors for each scale and asked, "Which SAM is most like how this movie clip made you feel?" (see Appendix A for additional details). Ratings of children's attentiveness to each clip were made using a 4-point Likert scale ( $1=$ attentive to the clip less than $25 \%$ of the time, $4=$ attentive to the clip $75-100 \%$ of the time). The order in which the child emotion 
self-rating scales were presented was randomized across clips to control for order effects. This procedure was repeated for each of the 20 clips in the battery. The research assistant informally assessed the child's mood at the end of the session (e.g., by asking the child what he or she thought about the clips overall, whether he or she had a favorite clip, etc.) to ensure that the child did not leave the session in a negative mood. Children and their parent each received gift cards at the end of the lab session. All sessions were videorecorded for subsequent coding of children's emotional responses to each clip.

\section{Child Emotion Coding}

Trained coders rated children's emotion states at the end of each clip to provide an objective measure of elicited emotional response. Coders were trained undergraduate research assistants who were blind to the child-report data, the nature of the film clips, and the order in which clips were presented. To maintain the blind, video recordings of the child did not include the film clip being viewed and videos were coded in the absence of accompanying sound. Because we felt that context was needed to elicit intended emotions, clips had expository material at the beginning that was often not emotioninducing; put differently, the emotion-inducing component of the film clips occurred toward the end of clips. For this reason, coders considered the last 30 seconds of presentation of each video clip, rating the most intense instance of positive affect, sadness, fear, and anger expressed during that epoch. To facilitate comparisons between coder and child ratings, both child self-reports and coder ratings were completed using the child emotion self-rating scales. All video recordings were coded by two independent coders. The average of the two ratings was used for analyses. 


\section{Results}

\section{Child Attentiveness to Film Clips}

Since low attentiveness to a film clip may attenuate elicited emotion, we examined mean experimenter ratings of children's attentiveness to clips as well as correlations between these ratings and mean coder-rated and child-reported emotion for each clip. Mean attentiveness ratings ranged from 3.54 to 4.00 across all clips (see Tables 2-4), indicating that, in general, children found the clips to be engaging. Attentiveness and both coder- and child-rated emotion for individual film clips were significantly associated in several cases. We report here only those correlations that reached significance, but provide all correlations between child attentiveness, coder-rated emotion, child-reported emotion, and child age across all clips in Tables 5-7.

The majority of significant correlations were in the expected direction, such that target emotions increased or nontarget emotions decreased as children's attentiveness to a clip increased. For coder ratings of child emotional response, there were significant negative correlations between attentiveness and positive affect for two clips intended to elicit fear, Jumanji $(r(35)=-.65, p<.001)$ and Honey, I Shrunk the Kids $(r(36)=-.33, p$ $<.05)$, and three clips intended to elicit dysphoria, The Cure $(r(34)=-.39, p<.05)$, Flash $(r(37)=-.37, p<.05)$, and Fly Away Home $(r(37)=-.51, p<.01)$. Significant positive correlations were found between attentiveness and child self-reports of a target emotion (i.e., sadness) for Stepmom $(r(33)=.42, p<.05)$ and The Cure $(r(35)=.36, p<.05)$. Contrary to expectations, attentiveness and a target emotion (i.e., sadness) were negatively correlated for What's Eating Gilbert Grape $(r(39)=-.35, p<.05)$. There were 
no significant associations between attentiveness and the SAM valence and arousal scales.

Lastly, attentiveness to clips may vary with children's age, potentially impacting clips' utility in MIPs with certain age groups. We therefore examined associations between children's attentiveness to clips and child age; none, however, reached significance (all $\mathrm{ps}>.06)$.

\section{Inter-Rater Reliability}

Inter-rater reliability for coding of children's emotional responses was estimated using two-way mixed effects, average measures, absolute intraclass correlation coefficients (ICC). However, ICCs are influenced by variance in coded behaviors (Koo \& Li, 2016), such that acceptable ICCs may not be obtained if variance is low, even when agreement between raters is high. In the current study, lower ICCs might be expected for affective behaviors that rarely occur, such as those not targeted by specific clips (e.g., fear during a clip intended to elicit positive affect). Therefore, to capture agreement on coding of nontarget emotions, we also report percent agreement between coders.

Reliability was generally good. For clips intended to evoke positive affect, reliability ranged from good to excellent for the target emotion and poor to excellent for nontarget emotions (Table 2), based on Cicchetti's (1994) guidelines. For coded sadness, reliability ranged from poor to excellent for the target emotion and poor to excellent for nontarget emotions (Table 3). For clips intended to evoke fear, reliability ranged from fair to excellent for the target emotion and poor to excellent for nontarget emotions (Table 4). For The Neverending Story, the ICC was poor for the target emotion.

\section{Within-Clip Comparisons of Target to Non-Target Emotions}


We used paired $t$-tests to examine whether clips elicited stronger emotional responses for the target emotion compared to other emotions. Findings that a clip elicited significantly more of the target emotion than nontarget emotions would support its utility in MIPs. For each clip, average coder ratings of child emotional response for the target emotion were compared to the average coder ratings for each of the three other emotions. The same procedure was then applied to the child-reported emotion ratings. The results of these analyses are displayed in Tables $2-4 .^{1}$

Table 2 shows comparisons of coder- and child-rated positive affect with sadness, fear, and anger for clips intended to evoke positive affect. All six clips elicited significantly higher positive affect than sadness, fear, and anger based on child selfreport. In addition, four clips (all except The Incredibles and E.T. the Extra-Terrestrial) elicited significantly higher positive affect than two or more nontarget emotions based on coder ratings of child emotional response. Mean positive affect ratings were significantly higher in all comparisons across coder and child measures for three of these clips-The Jungle Book, Unaccompanied Minors, and Hoosiers. Surprisingly, E.T. the ExtraTerrestrial elicited significantly higher coder ratings for two nontarget emotions (sadness and fear) compared to the target emotion (positive affect).

For clips intended to induce dysphoria, coder and child ratings of sadness were significantly higher than ratings of anger for all clips. In addition, none of these clips was found to elicit significantly more anger than positive affect or fear for either coder or

\footnotetext{
${ }^{1}$ In addition, in analyses not reported here, we compared clips in the same emotion category on mean ratings of the target emotion. Given that the pattern of findings was different for coder and child ratings (i.e., the pattern of which clips tended to elicit the greatest mean ratings of the target emotion), we do not report the results of these analyses here, but they are available from the author upon request.
} 
child ratings. In light of these findings, we hereafter focus solely on the sadness ratings for the dysphoric clips. As such, we report comparisons of coder and child ratings of sadness with positive affect, fear, and anger for these clips (Table 3). Five clips (all except Stepmom and What's Eating Gilbert Grape) elicited significantly higher sadness than positive affect, fear, and anger based on child self-report. In addition, all seven clips elicited significantly higher sadness than two or more nontarget emotions based on coder ratings of child emotional response. Mean sadness ratings were significantly higher in all comparisons across coder and child measures for three of these clips-Little Women, Flash, and The Cure.

Table 4 shows comparisons of coder and child ratings of fear with positive affect, sadness, and anger for clips intended to evoke fear. Five clips (all except Monster House and The Fox and the Hound) elicited significantly more fear than positive affect, sadness, and anger based on child self-report. In addition, six clips (all except The Fox and the Hound) elicited significantly more fear than two or more nontarget emotions based on coder ratings of child emotional response. Mean fear ratings were significantly higher in all comparisons across coder and child measures for five of these clips-Are You Afraid of the Dark?, Goosebumps, Jumanji, Harry Potter and the Chamber of Secrets, and Honey, I Shrunk the Kids.

\section{Clip Valence and Arousal}

To characterize the valence and arousal related to each clip based on the SAM scales, we present mean child-reported SAM valence and arousal ratings in Tables 2-4. In general, valence ratings were consistent with data from the child emotion self-rating scales. Mean valence ratings for clips intended to elicit positive affect ranged from 1.89 
to 4.29 (1.89 to 2.41 when excluding E.T. the Extra-Terrestrial, which performed poorly as a clip intended to elicit positive affect, as indicated above), indicating positive valence. In contrast, mean valence ratings for clips intended to elicit sadness (range: 4.82 to 6.89) and fear (range: 4.41 to 5.97) indicated negative valence. With respect to SAM arousal ratings, mean ratings indicated that, in general, children found all clips to be moderately arousing. Mean arousal ratings across emotion categories indicated that children generally found clips intended to elicit sadness (mean arousal ratings ranging from 5.00 to 5.71) less arousing than those intended to elicit positive affect (range: 4.38 to 5.03) or fear (range: 4.51 to 4.92 ).

\section{Associations Between Age and Emotional Responses to Clips}

The maturation of emotion-related processes over the course of development raises the possibility that age could influence the strength of emotional responses to clips. We therefore examined associations between child age and coder and child ratings of target emotions. Significant correlations were found only for coder ratings of children's emotional response. All significant correlations between age and coder ratings were positive, such that coders rated higher emotional intensity for older children. Child age was positively correlated with coder-rated sadness for Flash $(r=.36, p<.05)$ and Fly Away Home $(r=.37, p<.05)$, and coder-rated positive affect for E.T. the ExtraTerrestrial $(r=.44, p<.01)$. Lastly, we examined correlations between age and childreported SAM valence and arousal ratings. One significant positive correlation was found between child age and arousal for What's Eating Gilbert Grape $(r=.36, p<.05)$.

\section{Exploratory Analyses of Sex Differences in Target Emotional Responses}


Though our study was underpowered to detect sex differences in children's emotional responses to clips, we conducted exploratory analyses to investigate potential sex effects. Boys and girls were compared on emotion expression indexed via coder ratings and child-reported emotion ratings using independent samples $t$-tests. Table 8 shows tests of differences between boys and girls in reactivity to the target emotion for each clip. For coder-rated emotion, sex differences were found for only three clips; girls were rated as more fearful than boys for Jumanji and Are You Afraid of the Dark?. Similarly, girls were rated as showing more positive affect than boys in response to

\section{Unaccompanied Minors.}

Sex differences were also found for child-reported emotion. In general, girls reported higher emotional intensity in response to clips compared to boys in cases where significant differences were found. Specifically, girls reported significantly more fear than boys in response to Honey, I Shrunk the Kids. Furthermore, girls reported significantly more sadness than boys in response to Stepmom. Girls also reported significantly more positive affect than boys in response to Harry Potter and the Sorcerer's Stone. Sex differences were also examined using the child-reported SAM valence and arousal ratings for each clip. Only one significant difference was found: girls reported significantly higher arousal than boys in response to Harry Potter and the Chamber of Secrets.

Attentiveness to clips may also vary with children's sex, such that boys might find certain clips more or less engaging than girls. Since patterns of attentiveness might have implications for clips' suitability for eliciting emotion in boys versus girls, we examined associations between children's attentiveness to clips and child sex using independent 
samples $t$-tests. Only one significant difference was found: girls were more attentive to Little Women than boys.

\section{Associations Between ERC Subscales and Target Emotional Responses to Clips}

In exploratory analyses ${ }^{2}$, we examined one marker of the ecological validity of the battery by examining associations between caregiver-reported ERC scores and child and coder ratings of the target emotion for each film clip (Tables 5-7). For clips intended to elicit positive affect, we found a significant association between the ER subscale and coder-rated positive affect for E.T. the Extra-Terrestrial $(r=.35, p<.05)$ and a negative association between the LN subscale and coder-rated positive affect for Harry Potter and the Sorcerer's Stone $(r=-.39, p<.05)$. For clips intended to elicit sadness, we found a positive association between the ER subscale and child-rated sadness for Stepmom ( $r=$ $.46, p<.01)$. For clips intended to elicit fear, we found a positive association between the ER subscale and child-rated fear for Goosebumps $(r=.39, p<.05)$ and a negative association between the ER subscale and coder-rated fear for Harry Potter and the Chamber of Secrets $(r=-.41, p<.05)$. Overall-with the exception of the negative association between the ER subscale and ratings for Harry Potter and the Chamber of Secrets - these findings suggest that children who are better able to regulate their emotions display or report more of the target emotion in response to clips. In contrast, children who are less able to do so (i.e., have higher LN scores) displayed, but did not self-report, less positive affect in response to a clip intended to elicit this emotion.

\footnotetext{
2 These analyses were exploratory given the potential limitations of caregiver-reported child emotion regulation (Hourigan, Goodman, \& Southam-Gerow, 2011; Zeman et al., 2007) and because it was challenging to develop specific predictions for associations between reactivity to clips and the two ERC subscales. More specifically, one could anticipate that better emotion regulation might predict decreased reactivity to clips, but also increased reactivity in terms of "appropriate" affective responses to clips. Additionally, differences in associations between emotion regulation and clip reactivity might be expected based on child sex, the index of clip reactivity used (i.e., coder versus child ratings) and target emotion valence, as addressed in the Discussion section.
} 


\section{Discussion}

We aimed to develop and validate a relatively broad, developmentally sensitive battery of emotionally evocative film clips for children, successfully identifying clips that elicited the target emotion more so than nontargeted emotions according to both coderrated and child self-report indices of emotion. In general, we found few age-related effects on emotional response when considering both coder- and child-rated emotion, indicating that our film clips are generally equally effective for children varying in age from six to eight. All clips were acceptable to parents based on pilot data. Thus, this battery may serve as a useful tool for investigating emotional reactivity and regulation in middle childhood.

Mean child-reported ratings for the target emotion were higher than coder-rated emotion for all clips. This is perhaps not surprising given that children develop some capacity for self-monitoring and regulating their outward expressions of emotion by middle childhood (Zeman et al., 2007). At this stage of development, children are aware of display rules for social situations (Saarni, 1984) and may adapt their emotional responses to their social audience (Zeman et al., 2007). In addition, they increasingly use cognitive, and thus more covert, strategies for regulating their emotions (Compas et al., 2017). The presence of a video camera and an unfamiliar research assistant may have created social conditions under which children felt compelled to regulate and restrict their facial expressions of emotion, resulting in lower coder ratings of emotion.

In contrast to previous work (von Leupoldt et al., 2007), we found several age differences in children's emotional responses to clips. Significant correlations were found only for coder ratings of children's facial expressions, with coders rating higher 
emotional intensity for older children. Older children displayed higher sadness for two clips and higher positive affect for one clip. Notably, all three clips for which significant correlations were found featured the death of a character. Research suggests that children do not develop a complete understanding of the concept of death, such as its finality and irreversibility, until approximately age seven (Speece \& Brent, 1984). Thus, having a more mature understanding of death may have increased the poignancy of these clips for older children, such that they displayed higher sadness in response to the two clips intended to induce this emotion and, in the case of the clip intended to elicit positive affect (E.T. the Extra-Terrestrial), more positive emotion when a character comes back to life.

We assessed both sadness and anger in response to clips we anticipated would elicit dysphoric affect, given previous research showing that these emotions are often strongly interrelated in younger children (Dyson et al., 2012). However, we found that all clips in this category elicited significantly more sadness than anger according to both child- and coder-rated measures. While this finding may reflect the challenges of eliciting anger under laboratory conditions (Gross \& Levenson, 1995; Philippot, 1993; Zupan \& Babbage, 2017), it is perhaps better explained by the fact that most of our dysphoric film clips featured themes typically associated with sadness (e.g., grief and loss). Furthermore, content that could potentially elicit anger often occurred earlier in clips, with most clips concluding with sad content, thereby increasing the likelihood that sadness would be endorsed more frequently than anger by the end of the clip when ratings were collected. Future research is needed to identify and validate similar video stimuli for eliciting anger in young children. 
In addition to child self-reported emotions, we also collected self-reported hedonic valence and arousal ratings using the SAM scales. In general, the mean SAM valence ratings for clips were consistent with data from the discrete emotion scales, such that children rated clips intended to induce positive affect as more pleasant than clips intended to induce sadness or fear. These valence data may be of particular interest to investigators whose research questions call for eliciting broader emotional states in children rather than discrete emotions. With respect to the SAM arousal ratings, in general, children reported lower arousal in response to clips intended to induce sadness than clips intended to elicit positive affect or fear.

While sex differences were generally minimal, for the six clips where sex differences in the target emotion were found for either coder ( 3 clips) or child ( 3 clips) ratings, girls showed higher intensity of the target emotion, a finding consistent with previous work using video stimuli with children (von Leupoldt et al., 2007) and adults (Rottenberg et al., 2007). Interestingly, while we found sex differences for both coderrated and child-reported emotion, no single clip produced sex differences across both measures. According to child-reported ratings of emotion, girls reported significantly higher emotion for three clips (one fear, one sadness, and one positive affect). Similarly, according to coder ratings of children's facial expressions, girls displayed significantly more fear for two clips and positive affect for one clip. This finding is consistent with a recent meta-analysis of sex differences in observed emotion expression in children (Chaplin \& Aldao, 2013), which found that girls in middle childhood showed greater positive emotion, fear, and sadness than boys. It is unclear, however, whether these differential patterns of emotional responding for boys and girls are due to innate 
differences in emotional reactivity (Else-Quest, Hyde, Goldsmith, \& Van Hulle, 2006; Olino, Durbin, Klein, Hayden, \& Dyson, 2013) or socialization processes whereby girls are either encouraged (or at least permitted) to be more emotionally expressive while boys are encouraged to minimize emotional responses (Chaplin \& Aldao, 2013; Zeman \& Shipman, 1997). Importantly, while sex differences in children's emotional responses to clips appeared to be fairly limited based on our exploratory analyses, we reiterate that our sample lacked the power needed to reliably detect such effects. Further research in larger samples is needed to confirm whether sex effects exist for the clips in our battery.

Finally, in exploratory analyses, we investigated the ecological validity of the film clips in our battery by examining associations between children's emotion regulation, based on caregiver-reported ERC scores, and child and coder ratings of the target emotion for each film clip (i.e., children's emotional reactivity). Our findings that certain clips elicited more of the target emotion as children's ER subscale scores increased, or less of the target emotion as LN subscale scores increased, provide some evidence for ecological validity. That is, children's (self-reported or coder-rated) experience of the emotion expected for the situation (e.g., sadness in response to a clip intended to elicit sadness) was meaningfully related to concurrent caregiver ratings of children's tendency to display situationally appropriate affect (i.e., the ER subscale). Similarly, children's experience of positive affect for a clip intended to elicit this emotion (i.e., Harry Potter and the Sorcerer's Stone) was meaningfully related to caregiver ratings of children's dysregulated negative affect (i.e., the LN subscale).

While we found meaningful correlations between ERC scores and coder and child ratings of target emotions for five clips, overall, associations between caregiver 
perceptions of child emotion regulation and coder and child ratings were minimal. This could be due to several reasons. First, the activation of emotion (i.e., emotional reactivity) and regulation of emotion are distinct processes (Cole et al., 2004). We aimed to assess, through coder and child ratings, children's reactivity to clips; the ERC, however, does not distinguish between reactivity and regulation. It is possible that we would have found more associations had we used a measure that assessed caregiver-reported child emotional reactivity only. Second, caregiver perceptions of children's emotional functioning are potentially limited in that parents may be less able to accurately report on children's internal experiences (Hourigan et al., 2011; Zeman et al., 2007). Investigating potential associations between children's reactivity to clips and a self-report measure of their emotional reactivity presents an avenue for further research. Finally, the pattern of associations between ERC scores and children's reactivity to clips may differ across boys and girls, self-reported and observed reactivity, and the valence of the target emotion. For example, girls may be socialized to be more emotionally expressive (Chaplin \& Aldao, 2013), observed child reactivity might be more closely related to poor regulation (c.f., internal emotional reactivity), and social desirability may mean that children with better emotion regulation are less likely to endorse or express negative emotions compared to positive emotions. However, our study was underpowered to examine these more nuanced possibilities. Additional research with sufficient power to address these questions is therefore warranted.

\section{Recommendations for Use}

Clips are presented in Tables 2-4 in the order of their perceived utility based on (1) whether clips elicited significantly more of the target emotion than nontarget 
emotions according to both coder and child ratings, (2) the degree to which each clip elicited the target emotion considering both mean coder and child ratings of the target emotion, relative to other clips intended to elicit the same emotion (e.g., mean sadness in Little Women relative to mean sadness in Stepmom), and (3) the acceptability of ICCs and percent agreement for coder ratings of target emotions. Importantly, we make these recommendations with the aim of guiding, rather than replacing, the judgment of the researcher in selecting the stimuli best suited to their particular research context. Finally, we completed a neutral activity with children prior to attempting to induce emotion; although we do not know whether this influenced our findings, we recommend doing so when time permits.

\section{Limitations}

While our findings support the effectiveness of several film clips in eliciting an array of emotions in children, they must be considered in the context of several limitations. First, our sample was relatively small, thereby precluding adequate power to reliably detect certain effects, such as sex differences in emotional response to clips. Second, our sample was relatively homogenous in terms of age, ethnicity, and socioeconomic status. All children fell within the narrow age range of six to eight and the majority were white and middle-class. It is possible that the same battery may elicit different patterns of emotional responding in children from other demographic groups. Studies have shown, for instance, that cultural norms can influence children's emotional expressions (Morelen, Zeman, Perry-Parrish, \& Anderson, 2012). Considerable research has also shown that children's understanding, expression, and regulation of emotion varies significantly across developmental stages (Zeman, Cassano, Perry-Parrish, \& 
Stegall, 2006), such that our findings may not generalize beyond middle childhood.

Further, our findings are based on a community sample and may not generalize to clinical samples, particularly given research showing that children with psychological disorders show different profiles of emotion expression and regulation (Eisenberg et al., 2010). Additional research is therefore needed to validate this battery for use with diverse child populations.

Third, although pilot data indicated that parents found our film clips to be acceptable and the majority of parents who were approached by our team were willing to let their children participate, a small minority of families elected not to participate due to concerns that clips intended to elicit fear or dysphoria might be unduly upsetting to their child. Excluding these children may have biased our sample toward less sensitive children. Having said that, including children for whom the clips may have elicited highintensity emotion would have likely strengthened the magnitude of our effects.

Further research is needed to establish the stability of children's emotional responses to the film clips included in this battery over time. A limitation of our study is that we did not control for the potential effects of prior viewings of clips on children's emotional responses. Research with adults suggests that prior viewing of a clip allows one to access more contextual material and therefore heightens the experience of the target emotion during subsequent viewings (Gross \& Levenson, 1995). It is possible that children in our study had previously seen clips from our battery and that this may have intensified their emotional responses. This effect is likely to have been small, however, given previous work showing only a weak effect of prior viewing on emotional response (von Leupoldt et al., 2007). A second issue concerning the stability of emotional 
responses to clips is the possibility that clips may fail to elicit the same response across studies. Indeed, it is not uncommon for video stimuli to successfully elicit the target emotion in initial testing but fail to elicit the same response in subsequent implementations (e.g., Kovacs et al., 2015). While the fact that clips were validated using both self-report and observational methods strengthens our findings of their effectiveness, additional studies are needed to confirm the reliability and validity of the emotional responses they are intended to elicit. Additional studies might also validate the utility of these clips by showing that they elicit stronger effects than other MIPs for tasks that rely on mood induction to be successful (e.g., Self-Referent Encoding Task; Derry \& Kuiper, 1981).

Lastly, while research shows that children are able to provide valid self-reports of their emotions by age six (Durbin, 2010), there are several limitations associated with children's self-report. Firstly, social desirability bias may have prompted children to change or exaggerate their emotional responses to match what they perceived to be the "correct" emotion for a clip. Secondly, the effectiveness of clips in eliciting the intended emotion may have been magnified by the fact that children in middle childhood are prone to dichotomous self-report tendencies (Chambers \& Johnston, 2002). That is, children may have been more likely to use the extreme values of the emotion and SAM rating scales when reporting their emotional responses. Similarly, although we took care to emphasize to children that it was possible to feel more than one emotion in response to a clip, children may nonetheless have fixated on one particularly salient emotion to the exclusion of others in their reporting. It is possible that this self-report bias may have artificially inflated the differences between children's reported target and nontarget 
emotions. However, the fact that we found a similar pattern of results using observational ratings of children's facial expressions corroborates our findings from the child selfreport data.

In conclusion, using both child-reported emotion and coder ratings of children's facial expressions, we identified several film clips that successfully elicited either positive affect, sadness, or fear more so than nontargeted emotions. In reporting additional data on valence, arousal, sex and age differences, and caregiver-reported children's emotion regulation, we hoped to provide a rich dataset to inform the selection of video stimuli for addressing a wide range of research questions within the child emotion literature. We conclude with a call for further research that extends the reach of this battery to other populations and applications of interest to the field. 


\section{References}

Adrian, M., Zeman, J., \& Veits, G. (2011). Methodological implications of the affect revolution: A 35-year review of emotion regulation assessment in children. Journal of Experimental Child Psychology, 110, 171-197. doi:10.1016/j.jecp.2011.03.009

Aldao, A., Nolen-Hoeksema, S., \& Schweizer, S. (2010). Emotion-regulation strategies across psychopathology: A meta-analytic review. Clinical Psychology Review, 30, 217-237. doi:10.1016/j.cpr.2009.11.004

Bradley, M. M., \& Lang, P. J. (1994). Measuring emotion: The self-assessment manikin and the semantic differential. Journal of Behavior Therapy and Experimental Psychiatry, 25, 49-59. doi:10.1016/0005-7916(94)90063-9

Brenner, E. (2000). Mood induction in children: Methodological issues and clinical implications. Review of General Psychology, 4, 264-283. doi:10.1037/10892680.4.3.264

Carvalho, S., Leite, J., Galdo-Álvarez, S., \& Gonçalves, O. F. (2012). The Emotional Movie Database (EMDB): A self-report and psychophysiological study. Applied Psychophysiology and Biofeedback, 37, 279-294. doi:10.1007/s10484-012-92016

Chambers, C. T., \& Johnston, C. (2002). Developmental differences in children's use of rating scales. Journal of Pediatric Psychology, 27, 27-36. doi:10.1093/jpepsy/27.1.27 
Chaplin, T. M., \& Aldao, A. (2013). Gender differences in emotion expression in children: A meta-analytic review. Psychological Bulletin, 139, 735-765. doi:10.1037/a0030737

Christodoulou, J., \& Burke, D. M. (2016). Mood congruity and episodic memory in young children. Journal of Experimental Child Psychology, 142, 221-229. doi:10.1016/j.jecp.2015.09.019

Cicchetti, D. V. (1994). Guidelines, criteria, and rules of thumb for evaluating normed and standardized assessment instruments in psychology. Psychological Assessment, 6, 284-290. doi:10.1037/1040-3590.6.4.284

Cole, P. M., Martin, S. E., \& Dennis, T. A. (2004). Emotion regulation as a scientific construct: Methodological challenges and directions for child development research. Child Development, 75, 317-333. doi:10.1111/j.14678624.2004.00673.x

Compas, B. E., Jaser, S. S., Bettis, A. H., Watson, K. H., Grahn, M. A., Dunbar, J. P., .. . Thigpen, J. C. (2017). Coping, emotion regulation, and psychopathology in childhood and adolescence: A meta-analysis and narrative review. Psychological Bulletin, 143, 939-991. doi:10.1037/bul0000110

Davis, E. L., Quiñones-Camacho, L., \& Buss, K. A. (2016). The effects of distraction and reappraisal on children's parasympathetic regulation of sadness and fear. Journal of Experimental Child Psychology, 142, 344-358. doi:10.1016/j.jecp.2015.09.020

Derry, P. A., \& Kuiper, N. A. (1981). Schematic processing and self-reference in clinical depression. Journal of Abnormal Psychology, 90, 286-297. doi:10.1037/0021843X.90.4.286 
Durbin, C. E. (2010). Validity of young children's self-reports of their emotion in response to structured laboratory tasks. Emotion, 10, 519-535. doi:10.1037/a0019008

Dyson, M. W., Olino, T. M., Durbin, C. E., Goldsmith, H. H., \& Klein, D. N. (2012). The structure of temperament in preschoolers: A two-stage factor analytic approach. Emotion, 12, 44-57. doi:10.1037/a0025023

Eisenberg, N., Spinrad, T. L., \& Eggum, N. D. (2010). Emotion-related self-regulation and its relation to children's maladjustment. Annual Review of Clinical Psychology, 6, 495-525. doi:10.1146/annurev.clinpsy.121208.131208

Else-Quest, N. M., Hyde, J. S., Goldsmith, H. H., \& Van Hulle, C. A. (2006). Gender differences in temperament: A meta-analysis. Psychological Bulletin, 132, 33-72. doi:10.1037/0033-2909.132.1.33

Fischer, K. W., \& Tangney, J. P. (1995). Self-conscious emotions and the affect revolution: Framework and overview. In J. P. Tangney \& K. W. Fischer (Eds.), Self-conscious emotions: The psychology of shame, guilt, embarrassment, and pride (pp. 3-22). New York: Guilford.

Fredrickson, B. L. (2004). The broaden-and-build theory of positive emotions.

Philosophical Transactions of the Royal Society of London, Series B, Biological Sciences, 359, 1367-1378. doi:10.1098/rstb.2004.1512

Gilman, T. L., Shaheen, R., Nylocks, K. M., Halachoff, D., Chapman, J., Flynn, J. J., . . . Coifman, K. G. (2017). A film set for the elicitation of emotion in research: A comprehensive catalog derived from four decades of investigation. Behavior Research Methods, 49, 2061-2082. doi:10.3758/s13428-016-0842-x 
Goldschmidt, A. B., Tanofsky-Kraff, M., \& Wilfley, D. E. (2011). A laboratory-based study of mood and binge eating behavior in overweight children. Eating Behaviors, 12, 37-43. doi:10.1016/j.eatbeh.2010.11.001

Gotlib, I. H., Traill, S. K., Montoya, R. L., Joormann, J., \& Chang, K. (2005). Attention and memory biases in the offspring of parents with bipolar disorder: Indications from a pilot study. Journal of Child Psychology and Psychiatry, and Allied Disciplines, 46, 84-93. doi:10.1111/j.1469-7610.2004.00333.x

Greenbaum, P. E., Turner, C., Cook 3rd, E. W., \& Melamed, B. G. (1990). Dentists' voice control: Effects on children's disruptive and affective behavior. Health Psychology, 9, 546-558. doi:10.1037/0278-6133.9.5.546

Gross, J. J. (2013). Emotion regulation: Taking stock and moving forward. Emotion, 13, 359-365. doi:10.1037/a0032135

Gross, J. J., \& Levenson, R. W. (1995). Emotion elicitation using films. Cognition and Emotion, 9, 87-108. doi:10.1080/02699939508408966

Henderson, H. A., \& Fox, N. A. (2007). Considerations in studying emotion in infants and children. In J. A. Coan \& J. J. B. Allen (Eds.), The handbook of emotion elicitation and assessment (pp. 349-360). New York: Oxford University Press.

Hewig, J., Hagemann, D., Seifert, J., Gollwitzer, M., Naumann, E., \& Bartussek, D. (2005). A revised film set for the induction of basic emotions. Cognition and Emotion, 19, 1095-1109. doi:10.1080/02699930541000084

Hourigan, S. E., Goodman, K. L., \& Southam-Gerow, M. A. (2011). Discrepancies in parents' and children's reports of child emotion regulation. Journal of Experimental Child Psychology, 110, 198-212. doi:10.1016/j.jecp.2011.03.002 
Kim-Spoon, J., Cicchetti, D., \& Rogosch, F. A. (2013). A longitudinal study of emotion regulation, emotion lability-negativity, and internalizing symptomatology in maltreated and nonmaltreated children. Child Development, 84, 512-527. doi:10.1111/j.1467-8624.2012.01857.x

Koo, T. K., \& Li, M. Y. (2016). A guideline of selecting and reporting intraclass correlation coefficients for reliability research. Journal of Chiropractic Medicine, 15, 155-163. doi:10.1016/j.jcm.2016.02.012

Kovacs, M., Yaroslavsky, I., Rottenberg, J., George, C. J., Baji, I., Benák, I., . . Kapornai, K. (2015). Mood repair via attention refocusing or recall of positive autobiographical memories by adolescents with pediatric-onset major depression. Journal of Child Psychology and Psychiatry, and Allied Disciplines, 56, 11081117. doi:10.1111/jcpp.12376

Leventon, J. S., \& Bauer, P. J. (2016). Emotion regulation during the encoding of emotional stimuli: Effects on subsequent memory. Journal of Experimental Child Psychology, 142, 312-333. doi:10.1016/j.jecp.2015.09.024

Meehl, P. E. (1975). Hedonic capacity: Some conjectures. Bulletin of the Menninger Clinic, 39, 295-307. Reprinted in D. C. Clark \& J. Fawcett (Eds.), Anhedonia and affect deficit states (pp. 33-45). New York: PMA Publishing, 1987.

Miller, A. L., Kiely Gouley, K., Seifer, R., Dickstein, S., \& Shields, A. (2004). Emotions and behaviors in the Head Start classroom: Associations among observed dysregulation, social competence, and preschool adjustment. Early Education \& Development, 15, 147-166. doi:10.1207/s15566935eed1502_2 
Molina, P., Sala, M. N., Zappulla, C., Bonfigliuoli, C., Cavioni, V., Zanetti, M. A., ... Cicchetti, D. (2014). The Emotion Regulation Checklist-Italian translation. Validation of parent and teacher versions. European Journal of Developmental Psychology, 11, 624-634. doi:10.1080/17405629.2014.898581

Morelen, D., Zeman, J., Perry-Parrish, C., \& Anderson, E. (2012). Children's emotion regulation across and within nations: A comparison of Ghanaian, Kenyan, and American youth. British Journal of Developmental Psychology, 30, 415-431. doi:10.1111/j.2044-835X.2011.02050.x

Morrongiello, B. A., Stewart, J., Pope, K., Pogrebtsova, E., \& Boulay, K. (2015). Exploring relations between positive mood state and school-age children's risktaking. Journal of Pediatric Psychology, 40, 406-418. doi:10.1093/jpepsy/jsu100

Nolen-Hoeksema, S. (2012). Emotion regulation and psychopathology: The role of gender. Annual Review of Clinical Psychology, 8, 161-187. doi:10.1146/annurevclinpsy-032511-143109

Olino, T. M., Durbin, C. E., Klein, D. N., Hayden, E. P., \& Dyson, M. W. (2013). Gender differences in young children's temperament traits: Comparisons across observational and parent-report methods. Journal of Personality, 81, 119-129. doi:10.1111/jopy.12000

Philippot, P. (1993). Inducing and assessing differentiated emotion-feeling states in the laboratory. Cognition and Emotion, 7, 171-193. doi:10.1080/02699939308409183 
Rottenberg, J., Ray, R. R., \& Gross, J. J. (2007). Emotion elicitation using films. In J. A.

Coan \& J. J. B. Allen (Eds.), The handbook of emotion elicitation and assessment (pp. 9-28). New York: Oxford University Press.

Saarni, C. (1984). An observational study of children's attempts to monitor their expressive behavior. Child Development, 55, 1504-1513. doi:10.2307/1130020

Schaefer, A., Nils, F., Sanchez, X., \& Philippot, P. (2010). Assessing the effectiveness of a large database of emotion-eliciting films: A new tool for emotion researchers. Cognition and Emotion, 24, 1153-1172. doi:10.1080/02699930903274322

Schäfer, J. O., Naumann, E., Holmes, E. A., Tuschen-Caffier, B., \& Samson, A. C. (2017). Emotion regulation strategies in depressive and anxiety symptoms in youth: A meta-analytic review. Journal of Youth and Adolescence, 46, 261-276. doi:10.1007/s10964-016-0585-0

Shields, A., \& Cicchetti, D. (1997). Emotion regulation among school-age children: The development and validation of a new criterion Q-sort scale. Developmental Psychology, 33, 906-916. doi:10.1037//0012-1649.33.6.906

Speece, M. W., \& Brent, S. B. (1984). Children's understanding of death: A review of three components of a death concept. Child Development, 55, 1671-1686. doi:10.2307/1129915

Stegge, H., Meerum Terwogt, M., \& Koops, W. (1995). Mood congruity in children: Effects of age, imagery capability, and demand characteristics. International Journal of Behavioral Development, 18, 177-191. doi:10.1177/016502549501800110 
Vizueta, N., Patrick, C. J., Jiang, Y., Thomas, K. M., \& He, S. (2012). Dispositional fear, negative affectivity, and neuroimaging response to visually suppressed emotional faces. NeuroImage, 59, 761-771. doi:10.1016/j.neuroimage.2011.07.015

von Leupoldt, A., Rohde, J., Beregova, A., Thordsen-Sörensen, I., zur Nieden, J., \& Dahme, B. (2007). Films for eliciting emotional states in children. Behavior Research Methods, 39, 606-609. doi:10.3758/BF03193032

Westermann, R., Spies, K., Stahl, G., \& Hesse, F. W. (1996). Relative effectiveness and validity of mood induction procedures: A meta-analysis. European Journal of Social Psychology, 26, 557-580. doi:10.1002/(SICI)10990992(199607)26:4<557::AID-EJSP769>3.0.CO;2-4

Wong, D. L., \& Baker, C. M. (1988). Pain in children: Comparison of assessment scales. Pediatric Nursing, 14, 9-17. Retrieved from http://www.wongbakerfaces.org/wp-content/uploads/2010/08/pain-in-children.pdf

Zeman, J., Cassano, M., Perry-Parrish, C., \& Stegall, S. (2006). Emotion regulation in children and adolescents. Journal of Developmental and Behavioral Pediatrics, 27, 155-168. doi:10.1097/00004703-200604000-00014

Zeman, J., Klimes-Dougan, B., Cassano, M., \& Adrian, M. (2007). Measurement issues in emotion research with children and adolescents. Clinical Psychology: Science and Practice, 14, 377-401. doi:10.1111/j.1468-2850.2007.00098.x

Zeman, J., \& Shipman, K. (1997). Socio-contextual influences on expectancies for managing anger and sadness: The transition from middle childhood to adolescence. Developmental Psychology, 33, 917-924. doi:10.1037/00121649.33.6.917 
Zupan, B., \& Babbage, D. R. (2017). Film clips and narrative text as subjective emotion elicitation techniques. The Journal of Social Psychology, 157, 194-210. doi:10.1080/00224545.2016.1208138 
Table 1

Final battery of 20 film clips shown to children during laboratory sessions

\begin{tabular}{|c|c|c|c|}
\hline $\begin{array}{l}\text { Target } \\
\text { Emotion }\end{array}$ & Film & Description of Clip & $\begin{array}{l}\text { Clip } \\
\text { Length } \\
\text { (m:ss) }\end{array}$ \\
\hline \multicolumn{4}{|c|}{ Positive affect } \\
\hline & $\begin{array}{l}\text { E.T. the Extra-Terrestrial } \\
\text { (1982) }\end{array}$ & E.T. the alien revives himself & $2: 04$ \\
\hline & $\begin{array}{l}\text { Harry Potter and the } \\
\text { Sorcerer's Stone (2001) }\end{array}$ & $\begin{array}{l}\text { A boy makes a game-winning play for his } \\
\text { sports team }\end{array}$ & $2: 02$ \\
\hline & Hoosiers (1986) & A basketball player wins a game for the team & 2:08 \\
\hline & The Incredibles (2004) & $\begin{array}{l}\text { A girl interacts with her crush; a boy wins a } \\
\text { track meet }\end{array}$ & $1: 42$ \\
\hline & The Jungle Book (1967) & Mowgli meets Baloo the friendly bear & $2: 51$ \\
\hline & $\begin{array}{l}\text { Unaccompanied Minors } \\
\text { (2006) }\end{array}$ & A child plays music and dances & $2: 10$ \\
\hline \multicolumn{4}{|c|}{$\begin{array}{l}\text { Dysphoria } \\
\text { (sadness/anger) }\end{array}$} \\
\hline & The Cure (1995) & $\begin{array}{l}\text { A boy dies in hospital; his friend and the boy's } \\
\text { mother cry in a car }\end{array}$ & 3:56 \\
\hline & Flash (1997) & A boy's grandmother falls ill and dies at home & $4: 14$ \\
\hline & Fly Away Home (1996) & $\begin{array}{l}\text { A girl and her mother are in a car accident; the } \\
\text { girl wakes up in hospital and discovers her } \\
\text { mother has died }\end{array}$ & $3: 40$ \\
\hline & Little Women (1994) & A girl talks with her ill sister who then dies & $3: 45$ \\
\hline & $\begin{array}{l}\text { The Neverending Story } \\
\text { (1984) }\end{array}$ & $\begin{array}{l}\text { A boy tries to save his horse, which sinks in a } \\
\text { swamp }\end{array}$ & $3: 23$ \\
\hline & Stepmom (1998) & $\begin{array}{l}\text { An ill mother comforts her children about her } \\
\text { impending death }\end{array}$ & $2: 59$ \\
\hline & $\begin{array}{l}\text { What's Eating Gilbert } \\
\text { Grape (1993) }\end{array}$ & $\begin{array}{l}\text { A boy with autism gets beaten up; a boy finds } \\
\text { his mother dead in her bed }\end{array}$ & $3: 14$ \\
\hline \multicolumn{4}{|l|}{ Fear } \\
\hline & $\begin{array}{l}\text { Are You Afraid of the } \\
\text { Dark?, Season 1, Episode 3, } \\
\text { "The Tale of the Lonely } \\
\text { Ghost" (1992) }\end{array}$ & $\begin{array}{l}\text { A girl discovers a message drawn on a wall } \\
\text { and sees a ghost in a mirror }\end{array}$ & $2: 10$ \\
\hline & $\begin{array}{l}\text { The Fox and the Hound } \\
\text { (1981) [Animated] }\end{array}$ & A man and his dog are attacked by a bear & $1: 15$ \\
\hline & $\begin{array}{l}\text { Goosebumps, Season } 2 \\
\text { Episode 24, "Night of the } \\
\text { Living Dummy III" (1997) }\end{array}$ & $\begin{array}{l}\text { A girl enters an attic and discovers a } \\
\text { ventriloquist's dummy that comes alive }\end{array}$ & $1: 24$ \\
\hline & $\begin{array}{l}\text { Harry Potter and the } \\
\text { Chamber of Secrets (2002) }\end{array}$ & A boy is chased by a giant snake & $1: 10$ \\
\hline & $\begin{array}{l}\text { Honey, I Shrunk the Kids } \\
\text { (1989) }\end{array}$ & A giant scorpion chases children & $2: 18$ \\
\hline & Jumanji (1995) & $\begin{array}{l}\text { A boy is sucked into a board game; bats come } \\
\text { out of a fireplace }\end{array}$ & $1: 10$ \\
\hline & $\begin{array}{l}\text { Monster House (2006) } \\
\text { [Animated] }\end{array}$ & $\begin{array}{l}\text { An elderly man yells at a little girl to get off } \\
\text { his lawn }\end{array}$ & $1: 16$ \\
\hline
\end{tabular}


Table 2

Clips intended to evoke positive affect

Descriptive statistics and paired $\mathrm{t}$-tests comparing positive affect to sadness, fear, and anger using coder ratings of emotional response and child self-reported emotion

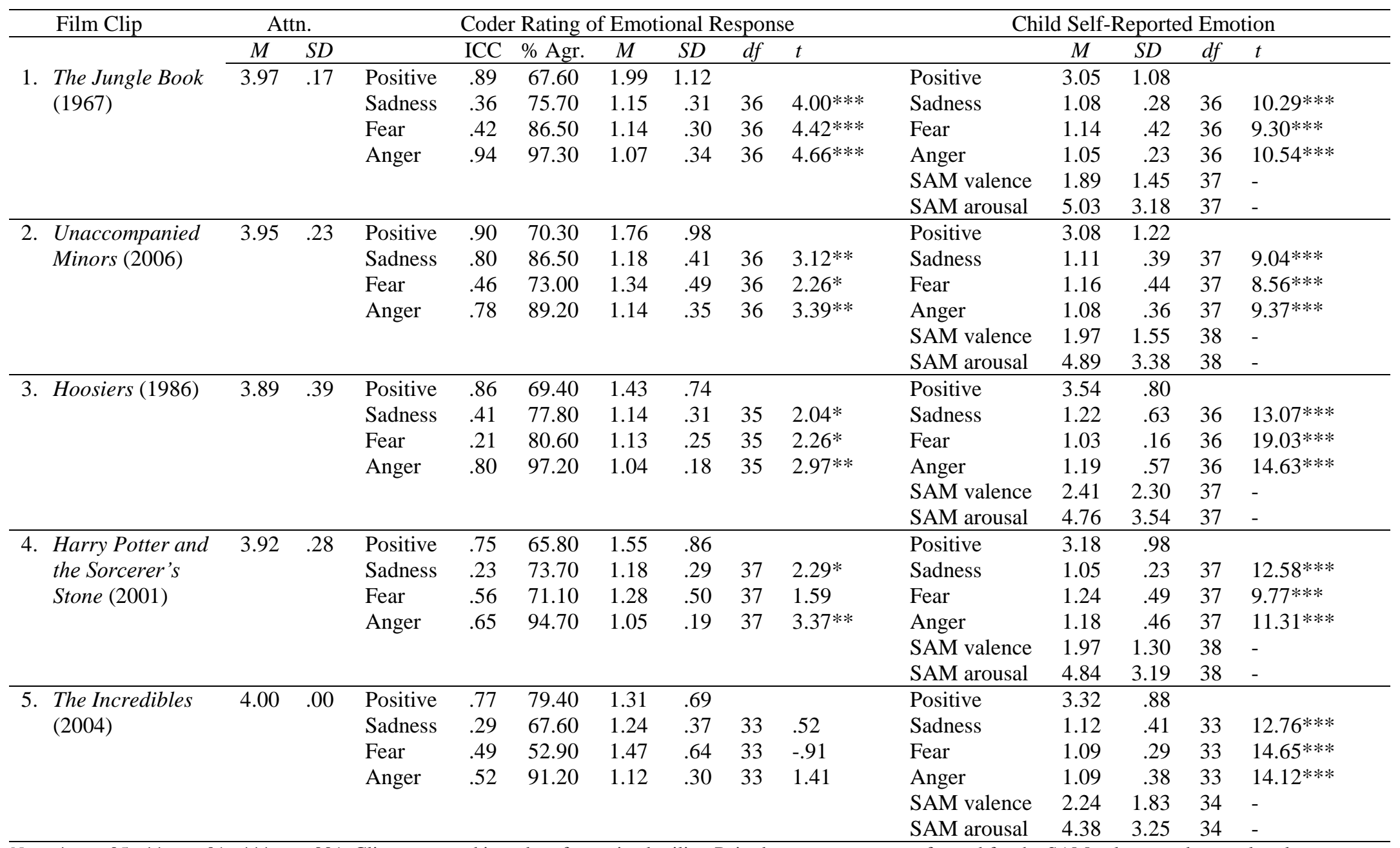

Note. $* p<.05, * * p<.01, * * * p<.001$. Clips presented in order of perceived utility. Paired $t$-tests were not performed for the SAM valence and arousal scales. 
Table 2 Continued

\begin{tabular}{|c|c|c|c|c|c|c|c|c|c|c|c|c|c|c|}
\hline Film Clip & \multicolumn{2}{|c|}{ Attn. } & \multicolumn{7}{|c|}{ Coder Rating of Emotional Response } & \multicolumn{5}{|c|}{ Child Self-Reported Emotion } \\
\hline \multirow{7}{*}{$\begin{array}{l}E x \\
\text { ial }\end{array}$} & $M$ & $S D$ & & ICC & $\%$ Agr. & $M$ & $S D$ & $d f$ & $t$ & & $M$ & $S D$ & $d f$ & $t$ \\
\hline & 3.86 & .42 & Positive & .71 & 89.50 & 1.16 & .48 & & & Positive & 2.32 & 1.09 & & \\
\hline & & & Sadness & .64 & 57.90 & 1.53 & .64 & 37 & $-2.64 *$ & Sadness & 1.63 & .82 & 37 & $3.15^{* *}$ \\
\hline & & & Fear & .59 & 47.40 & 1.64 & .73 & 37 & $-3.27 * *$ & Fear & 1.47 & .86 & 37 & $4.18 * * *$ \\
\hline & & & Anger & .34 & 86.80 & 1.14 & .33 & 37 & .13 & Anger & 1.18 & .56 & 37 & $6.37 * * *$ \\
\hline & & & & & & & & & & SAM valence & 4.29 & 2.52 & 38 & - \\
\hline & & & & & & & & & & SAM arousal & 4.63 & 2.74 & 38 & - \\
\hline
\end{tabular}

Note. $* p<.05, * * p<.01, * * * p<.001$. Clips presented in order of perceived utility. Paired $t$-tests were not performed for the SAM valence and arousal scales. 
Table 3

Clips intended to evoke dysphoria (i.e., sadness and/or anger)

Descriptive statistics and paired $\mathrm{t}$-tests comparing sadness to positive affect, fear, and anger using coder ratings of emotional response and child self-reported emotion

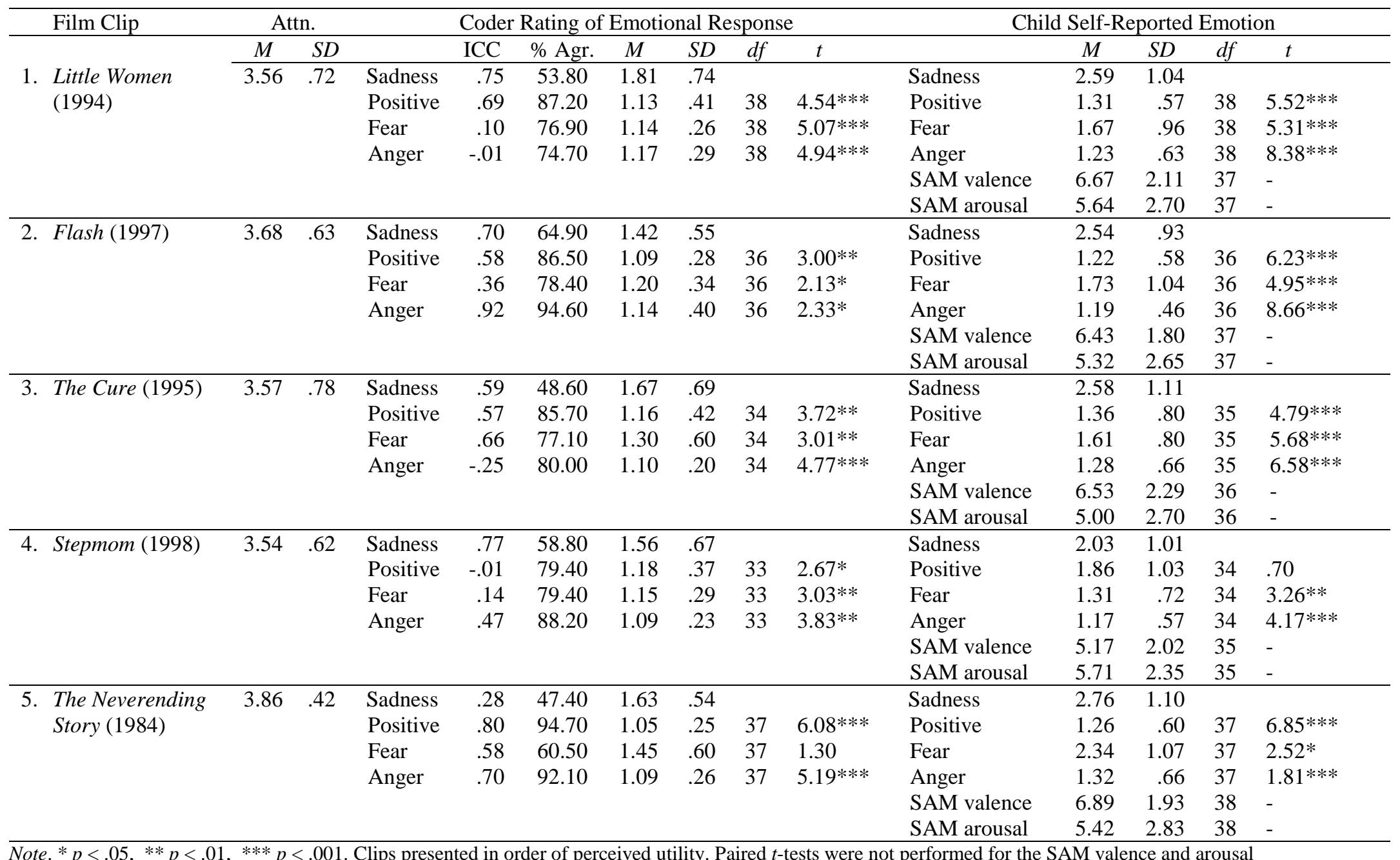

Note. $* p<.05, * * p<.01, * * * p<.001$. Clips presented in order of perceived utility. Paired $t$-tests were not performed for the SAM valence and arousal scales. 
Table 3 Continued

\begin{tabular}{|c|c|c|c|c|c|c|c|c|c|c|c|c|c|c|}
\hline \multirow[t]{2}{*}{ Film Clip } & \multicolumn{2}{|c|}{ Attn. } & \multicolumn{7}{|c|}{ Coder Rating of Emotional Response } & \multicolumn{5}{|c|}{ Child Self-Reported Emotion } \\
\hline & $M$ & $S D$ & & ICC & $\%$ Agr. & $M$ & $S D$ & $d f$ & $t$ & & $M$ & $S D$ & $d f$ & $t$ \\
\hline \multirow{6}{*}{$\begin{array}{l}\text { 6. What's Eating } \\
\text { Gilbert Grape } \\
\text { (1993) }\end{array}$} & 3.95 & .22 & Sadness & .76 & 64.10 & 1.56 & .61 & & & Sadness & 1.97 & 1.04 & & \\
\hline & & & Positive & .64 & 76.90 & 1.31 & .66 & 38 & 1.66 & Positive & 1.85 & 1.11 & 38 & .45 \\
\hline & & & Fear & -.10 & 66.70 & 1.19 & .27 & 38 & $3.25^{* *}$ & Fear & 1.54 & .85 & 38 & $2.81 * *$ \\
\hline & & & Anger & .40 & 82.10 & 1.21 & .41 & 38 & $3.26 * *$ & Anger & 1.26 & .64 & 38 & $4.49 * * *$ \\
\hline & & & & & & & & & & SAM valence & 4.82 & 2.57 & 39 & - \\
\hline & & & & & & & & & & SAM arousal & 5.05 & 3.01 & 39 & - \\
\hline \multirow{6}{*}{$\begin{array}{l}\text { 7. Fly Away Home } \\
\text { (1996) }\end{array}$} & 3.68 & .66 & Sadness & .47 & 59.50 & 1.38 & .48 & & & Sadness & 2.47 & 1.11 & & \\
\hline & & & Positive & -.09 & 89.20 & 1.05 & .16 & 36 & $3.72 * *$ & Positive & 1.37 & .71 & 37 & $4.71 * * *$ \\
\hline & & & Fear & .60 & 59.50 & 1.51 & .55 & 36 & -1.09 & Fear & 2.05 & 1.06 & 37 & $2.66^{*}$ \\
\hline & & & Anger & -.10 & 83.80 & 1.08 & .19 & 36 & $4.35 * * *$ & Anger & 1.21 & .62 & 37 & $7.03 * * *$ \\
\hline & & & & & & & & & & SAM valence & 6.45 & 2.27 & 38 & - \\
\hline & & & & & & & & & & SAM arousal & 5.45 & 2.99 & 38 & - \\
\hline
\end{tabular}

Note. $* p<.05, * * p<.01, * * * p<.001$. Clips presented in order of perceived utility. Paired $t$-tests were not performed for the SAM valence and arousal scales. 
Table 4

Clips intended to evoke fear

Descriptive statistics and paired $\mathrm{t}$-tests comparing fear to positive affect, sadness, and anger using coder ratings of emotional response and child self-reported emotion

\begin{tabular}{|c|c|c|c|c|c|c|c|c|c|c|c|c|c|c|}
\hline Film Clip & \multicolumn{2}{|c|}{ Attn. } & \multicolumn{7}{|c|}{ Coder Rating of Emotional Response } & \multicolumn{5}{|c|}{ Child Self-Reported Emotion } \\
\hline \multirow{7}{*}{$\begin{array}{l}\text { 1. Are You Afraid of } \\
\text { the Dark?, Season } \\
\text { 1, Episode 3, "Tale } \\
\text { of the Lonely } \\
\text { Ghost" (1992) }\end{array}$} & $M$ & $S D$ & & ICC & $\%$ Agr. & $M$ & $S D$ & $d f$ & $t$ & & $M$ & $S D$ & $d f$ & $t$ \\
\hline & 3.83 & .51 & Fear & .78 & 52.80 & 1.88 & .94 & & & Fear & 2.89 & 1.04 & & \\
\hline & & & Positive & .73 & 83.30 & 1.18 & .48 & 35 & $4.07 * * *$ & Positive & 1.50 & .81 & 35 & $5.56 * * *$ \\
\hline & & & Sadness & .62 & 69.40 & 1.35 & .56 & 35 & $2.86 * *$ & Sadness & 1.53 & .77 & 35 & $7.26 * * *$ \\
\hline & & & Anger & -.06 & 94.40 & 1.03 & .12 & 35 & $5.45 * * *$ & Anger & 1.50 & .91 & 35 & $7.94 * * *$ \\
\hline & & & & & & & & & & SAM valence & 5.86 & 2.26 & 36 & - \\
\hline & & & & & & & & & & SAM arousal & 4.92 & 2.79 & 36 & - \\
\hline 2. Goosebumps, & 3.97 & .17 & Fear & .76 & 45.90 & 2.01 & 1.00 & & & Fear & 2.49 & 1.02 & & \\
\hline Season 2 Episode & & & Positive & .00 & 94.60 & 1.05 & .26 & 36 & $5.99 * * *$ & Positive & 1.57 & .93 & 36 & $3.31 * *$ \\
\hline 24, "Night of the & & & Sadness & .68 & 51.40 & 1.46 & .62 & 36 & $2.84 * *$ & Sadness & 1.38 & .68 & 36 & $6.43 * * *$ \\
\hline Living Dummy III" & & & Anger & .32 & 86.50 & 1.15 & .33 & 36 & $5.07 * * *$ & Anger & 1.35 & .89 & 36 & $5.84 * * *$ \\
\hline (1997) & & & & & & & & & & SAM valence & 5.43 & 2.10 & 37 & - \\
\hline & & & & & & & & & & SAM arousal & 4.86 & 2.49 & 37 & - \\
\hline 3. Jumanji (1995) & 3.91 & .28 & Fear & .65 & 52.80 & 1.81 & .86 & & & Fear & 2.44 & 1.05 & & \\
\hline & & & Positive & .70 & 83.30 & 1.24 & .59 & 35 & $2.84 * *$ & Positive & 1.58 & 1.00 & 35 & $3.08 * *$ \\
\hline & & & Sadness & .69 & 66.70 & 1.36 & .52 & 35 & $2.73 *$ & Sadness & 1.61 & .90 & 35 & $5.00 * * *$ \\
\hline & & & Anger & .44 & 88.90 & 1.08 & .22 & 35 & $5.16 * * *$ & Anger & 1.28 & .66 & 35 & $6.63 * * *$ \\
\hline & & & & & & & & & & SAM arousal & 4.92 & 2.96 & 36 & - \\
\hline 4. Harry Potter and & 4.00 & .00 & Fear & .64 & 52.60 & 1.59 & .71 & & & Fear & 2.55 & 1.16 & & \\
\hline the Chamber of & & & Positive & .95 & 94.70 & 1.11 & .50 & 37 & $3.22 * *$ & Positive & 1.45 & .86 & 37 & $4.24 * * *$ \\
\hline Secrets (2002) & & & Sadness & .70 & 76.30 & 1.28 & .45 & 37 & $2.19 *$ & Sadness & 1.42 & .79 & 37 & $6.10 * * *$ \\
\hline & & & Anger & .09 & 78.90 & 1.15 & .28 & 37 & $3.47 * *$ & Anger & 1.37 & .71 & 37 & $5.65 * * *$ \\
\hline & & & & & & & & & & SAM valence & 5.84 & 1.91 & 38 & - \\
\hline & & & & & & & & & & SAM arousal & 4.87 & 2.75 & 38 & - \\
\hline 5. Honey, I Shrunk the & 3.94 & .23 & Fear & .41 & 40.50 & 1.70 & .69 & & & Fear & 2.35 & 1.06 & & \\
\hline Kids (1989) & & & Positive & .34 & 86.50 & 1.15 & .44 & 36 & $4.53 * * *$ & Positive & 1.46 & .96 & 36 & $3.20 * *$ \\
\hline & & & Sadness & .75 & 70.30 & 1.36 & .55 & 36 & $2.37 *$ & Sadness & 1.84 & .99 & 36 & $3.07 * *$ \\
\hline & & & Anger & .44 & 75.70 & 1.22 & .38 & 36 & $4.10 * * *$ & Anger & 1.30 & .66 & 36 & $5.94 * * *$ \\
\hline & & & & & & & & & & SAM valence & 5.97 & 2.50 & 37 & - \\
\hline & & & & & & & & & & SAM arousal & 4.65 & 2.69 & 37 & - \\
\hline
\end{tabular}
scales. 
Table 4 Continued

\begin{tabular}{|c|c|c|c|c|c|c|c|c|c|c|c|c|c|c|}
\hline Film Clip & \multicolumn{2}{|c|}{ Attn. } & \multicolumn{7}{|c|}{ Coder Rating of Emotional Response } & \multicolumn{5}{|c|}{ Child Self-Reported Emotion } \\
\hline \multirow{7}{*}{6.} & $M$ & $S D$ & & ICC & $\%$ Agr. & $M$ & $S D$ & $d f$ & $t$ & & $M$ & $S D$ & $d f$ & $t$ \\
\hline & 3.94 & .34 & Fear & .66 & 62.20 & 1.59 & .72 & & & Fear & 2.27 & 1.10 & & \\
\hline & & & Positive & .94 & 89.20 & 1.22 & .67 & 36 & $2.15^{*}$ & Positive & 1.62 & 1.06 & 36 & $2.34 *$ \\
\hline & & & Sadness & .40 & 54.10 & 1.47 & .51 & 36 & .82 & Sadness & 1.95 & .91 & 36 & 1.78 \\
\hline & & & Anger & .54 & 75.70 & 1.26 & .37 & 36 & $2.83 * *$ & Anger & 1.68 & .97 & 36 & $3.39 * *$ \\
\hline & & & & & & & & & & SAM valence & 5.49 & 2.46 & 37 & - \\
\hline & & & & & & & & & & SAM arousal & 4.84 & 2.73 & 37 & - \\
\hline 7. The Fox and the & 3.97 & .17 & Fear & .52 & 63.90 & 1.56 & .66 & & & Fear & 2.00 & 1.15 & & \\
\hline Hound (1981) & & & Positive & .97 & 91.70 & 1.31 & .85 & 35 & 1.38 & Positive & 1.86 & 1.06 & 36 & .44 \\
\hline [Animated] & & & Sadness & .62 & 58.30 & 1.50 & .57 & 35 & .38 & Sadness & 1.65 & .79 & 36 & 1.88 \\
\hline & & & Anger & .79 & 72.20 & 1.28 & .58 & 35 & 1.84 & Anger & 1.43 & .83 & 36 & $3.23 * *$ \\
\hline & & & & & & & & & & SAM valence & 4.41 & 2.11 & 37 & - \\
\hline & & & & & & & & & & SAM arousal & 4.51 & 2.60 & 37 & - \\
\hline
\end{tabular}

Note. $* p<.05, * * p<.01, * * * p<.001$. Clips presented in order of perceived utility. Paired $t$-tests were not performed for the SAM valence and arousal scales. 
Table 5

Correlations between child age, coder-rated positive affect, child-reported positive affect, child attentiveness, and ERC subscales for clips intended to evoke positive affect

\begin{tabular}{|c|c|c|c|c|c|c|c|c|c|c|c|c|c|c|c|c|c|c|c|c|}
\hline & 1 & 2 & 3 & 4 & 5 & 6 & 7 & 8 & 9 & 10 & 11 & 12 & 13 & 14 & 15 & 16 & 17 & 18 & 19 & 20 \\
\hline 1. Child Age & - & & & & & & & & & & & & & & & & & & & \\
\hline 2. JungleBook_Coder & .01 & - & & & & & & & & & & & & & & & & & & \\
\hline 3. JungleBook_Child & .10 & .05 & - & & & & & & & & & & & & & & & & & \\
\hline 5. UnaccMinors_Coder & .06 & .16 & -.12 & .05 & - & & & & & & & & & & & & & & & \\
\hline 6. UnaccMinors_Child & .25 & .12 & .26 & .16 & .30 & - & & & & & & & & & & & & & & \\
\hline 7. UnaccMinors_Attn & .14 & .05 & .12 & -.04 & .00 & -.08 & - & & & & & & & & & & & & & \\
\hline 8. Hoosiers_Coder & -.07 & -.05 & .13 & -.01 & $.45^{* *}$ & .29 & -.02 & - & & & & & & & & & & & & \\
\hline 9. Hoosiers_Child & .17 & -.16 & .25 & -.09 & .24 & $.36^{*}$ & -.15 & .18 & - & & & & & & & & & & & \\
\hline 10. Hoosiers_Attn & -.16 & .05 & -.19 & -.05 & -.05 & .01 & -.07 & -.12 & -.16 & - & & & & & & & & & & \\
\hline 11. HPSorcerer_Coder & .07 & -.04 & -.02 & .12 & .15 & .01 & -.12 & .07 & .13 & $-.34^{*}$ & - & & & & & & & & & \\
\hline 12. HPSorcerer_Child & .06 & .21 & $.34^{*}$ & -.15 & $.33^{*}$ & $.33^{*}$ & .16 & .27 & $.38^{*}$ & -.03 & -.06 & - & & & & & & & & \\
\hline 13. HPSorcerer_Attn & .33 & -.01 & -.10 & $.56^{* *}$ & -.12 & .01 & $.36^{*}$ & -.31 & -.17 & .17 & -.03 & -.05 & - & & & & & & & \\
\hline 14. Incredibles_Coder & .03 & -.01 & -.16 & .08 & $.41^{*}$ & .09 & .12 & .00 & .06 & -.14 & .23 & .11 & .15 & - & & & & & & \\
\hline 15. Incredibles_Child & .08 & .07 & $.37^{*}$ & -.14 & -.11 & .28 & -.04 & -.05 & $.46^{* *}$ & -.23 & -.12 & .11 & -.25 & .21 & - & & & & & \\
\hline 16. Incredibles_Attn ${ }^{\mathrm{a}}$ & - & - & - & - & - & - & - & - & - & - & - & - & - & - & - & - & & & & \\
\hline 19. ET_Attn & .16 & .02 & -.13 & -.05 & .20 & -.06 & $.75^{* *}$ & .17 & -.16 & .28 & $-.35^{*}$ & .07 & $.38^{*}$ & .09 & -.25 & - & .11 & .10 & - & \\
\hline 20. ERC_ER & $.42^{*}$ & .19 & .24 & -.20 & .16 & .25 & .01 & .20 & .16 & -.10 & .20 & .30 & -.15 & -.13 & -.24 & - & $.35^{*}$ & .23 & -.08 & - \\
\hline 21. ERC_LN & -.32 & -.12 & -.24 & .16 & .06 & -.12 & .04 & -.02 & -.01 & -.01 & $-.39^{*}$ & -.28 & .05 & .03 & .20 & - & -.22 & -.17 & .15 & $-.67^{* *}-$ \\
\hline
\end{tabular}

Note. ${ }^{*} p<.05, * * p<.01$. JungleBook = The Jungle Book; UnaccMinors = Unaccompanied Minors; HPSorcerer = Harry Potter and the Sorcerer's Stone; Incredibles = The Incredibles; ET = E.T. the Extra-Terrestrial; Emotion Regulation Checklist (Shields \& Cicchetti, 1997); ER = Emotion Regulation Subscale; LN = Lability/Negativity Subscale.

${ }^{a}$ Correlations with Incredibles_Attn are not shown because this variable was a constant (i.e., attention was rated 4 for all children). 
Table 6

Correlations between child age, coder-rated sadness, child-reported sadness, child attentiveness, and ERC subscales for clips intended to evoke dysphoria (i.e., sadness and/or anger)

\begin{tabular}{|c|c|c|c|c|c|c|c|c|c|c|c|c|c|c|c|c|c|c|c|c|c|c|c|}
\hline & 1 & 2 & 3 & 4 & 5 & 6 & 7 & 8 & 9 & 10 & 11 & 12 & 13 & 14 & 15 & 16 & 17 & 18 & 19 & 20 & 21 & $22 \quad 23$ & 24 \\
\hline 1. Child Age & - & & & & & & & & & & & & & & & & & & & & & & \\
\hline 2. LitWomen_Coder & .20 & - & & & & & & & & & & & & & & & & & & & & & \\
\hline 3. LitWomen_Child & -.09 & .15 & - & & & & & & & & & & & & & & & & & & & & \\
\hline 4. LitWomen_Attn & .23 & -.01 & .14 & - & & & & & & & & & & & & & & & & & & & \\
\hline 5. Flash_Coder & $.36^{*}$ & .10 & -.08 & .19 & - & & & & & & & & & & & & & & & & & & \\
\hline 6. Flash_Child & -.18 & -.09 & $.74^{* *}$ & .07 & -.10 & - & & & & & & & & & & & & & & & & & \\
\hline 7. Flash_Attn & .08 & .00 & .02 & $.42^{*}$ & -.04 & .12 & - & & & & & & & & & & & & & & & & \\
\hline 8. TheCure_Coder & .01 & .11 & .25 & -.07 & -.08 & .20 & -.19 & - & & & & & & & & & & & & & & & \\
\hline 10. TheCure_Attn & .00 & .17 & .27 & .33 & -.09 & .29 & $.72^{* *}$ & -.03 & $.36^{*}$ & - & & & & & & & & & & & & & \\
\hline 11. Stepmom_Coder & -.06 & -.01 & .17 & -.08 & -.11 & .19 & $-.44^{* *}$ & * $.43^{*}$ & .12 & -.24 & - & & & & & & & & & & & & \\
\hline 12. Stepmom_Child & -.01 & .01 & $.35^{*}$ & .31 & .01 & $.42^{*}$ & .13 & .11 & $.42^{*}$ & .13 & -.21 & - & & & & & & & & & & & \\
\hline 13. Stepmom_Attn & .13 & -.05 & .16 & .33 & .16 & .23 & $.43^{*}$ & -.20 & .17 & $.45^{*}$ & -.29 & $.42^{*}$ & - & & & & & & & & & & \\
\hline 14. NevStory_Coder & .02 & .16 & .12 & -.05 & .16 & .14 & .15 & .22 & .24 & .23 & .04 & -.01 & .07 & - & & & & & & & & & \\
\hline 15. NevStory_Child & .00 & -.01 & $.52^{* *}$ & .10 & -.07 & $.55^{* *}$ & .07 & .06 & $.41^{*}$ & .17 & .16 & .27 & .17 & $.37^{*}$ & - & & & & & & & & \\
\hline 16. NevStory_Attn & .22 & .10 & .13 & $.34^{*}$ & .02 & .07 & $.36^{*}$ & .13 & .32 & $.60^{* *}$ & .04 & -.05 & -.03 & .13 & -.07 & - & & & & & & & \\
\hline 17. GilbGrape_Coder & .05 & .26 & .02 & .10 & -.01 & -.23 & -.17 & .06 & -.16 & -.05 & .18 & -.25 & -.16 & -.13 & $-.35^{*}$ & .20 & - & & & & & & \\
\hline 19. GilbGrape_Attn & .14 & .10 & $-.32^{*}$ & -.14 & -.04 & -.25 & .26 & .15 & -.20 & .18 & -.07 & -.24 & .02 & -.05 & -.27 & .21 & .02 & $-.35^{*}$ & - & & & & \\
\hline 20. FlyHome_Coder & $.37^{*}$ & .19 & .12 & .17 & .16 & .09 & .30 & -.07 & $.34^{*}$ & $.38^{*}$ & .01 & .33 & .24 & -.04 & .03 & .28 & .21 & .03 & .19 & - & & & \\
\hline 21. FlyHome_Child & -.06 & .04 & $.59^{* *}$ & .29 & .06 & $.56^{* *}$ & $.33^{*}$ & -.05 & $.68^{* *}$ & $.45^{* *}$ & -.09 & $.50^{* * *}$ & .25 & .22 & $.69^{* *}$ & .21 & -.13 & $.56^{* *}$ & -.22 & .26 & - & & \\
\hline 22. FlyHome_Attn & .26 & .19 & -.14 & $.34^{*}$ & .09 & -.09 & $.57^{* *}$ & $-.38^{*}$ & -.04 & $.65^{* *}$ & $-.39^{*}$ & -.10 & .29 & .32 & -.08 & $.45^{* *}$ & .20 & .04 & .07 & .23 & .06 & - & \\
\hline 23. ERC_ER & $.42 *$ & .19 & .09 & .12 & -.04 & .10 & -.13 & .23 & .12 & -.01 & .28 & $.46^{* *}$ & .13 & .16 & .27 & .03 & -.08 & .26 & .02 & .27 & .12 & $-.02-$ & \\
\hline 24. ERC_LN & -.32 & -.14 & -.02 & -.03 & -.18 & -.09 & .07 & -.14 & -.11 & .14 & -.27 & -.19 & -.08 & -.27 & -.18 & .12 & .14 & -.12 & -.15 & -.30 & -.00 & $.04-.67^{* *}-$ & - \\
\hline
\end{tabular}

$\mathrm{ERC}=$ Emotion Regulation Checklist (Shields \& Cicchetti, 1997); ER = Emotion Regulation Subscale; LN = Lability/Negativity Subscale. 
Table 7

Correlations between child age, coder-rated fear, child-reported fear, child attentiveness, and ERC subscales for clips intended to evoke fear

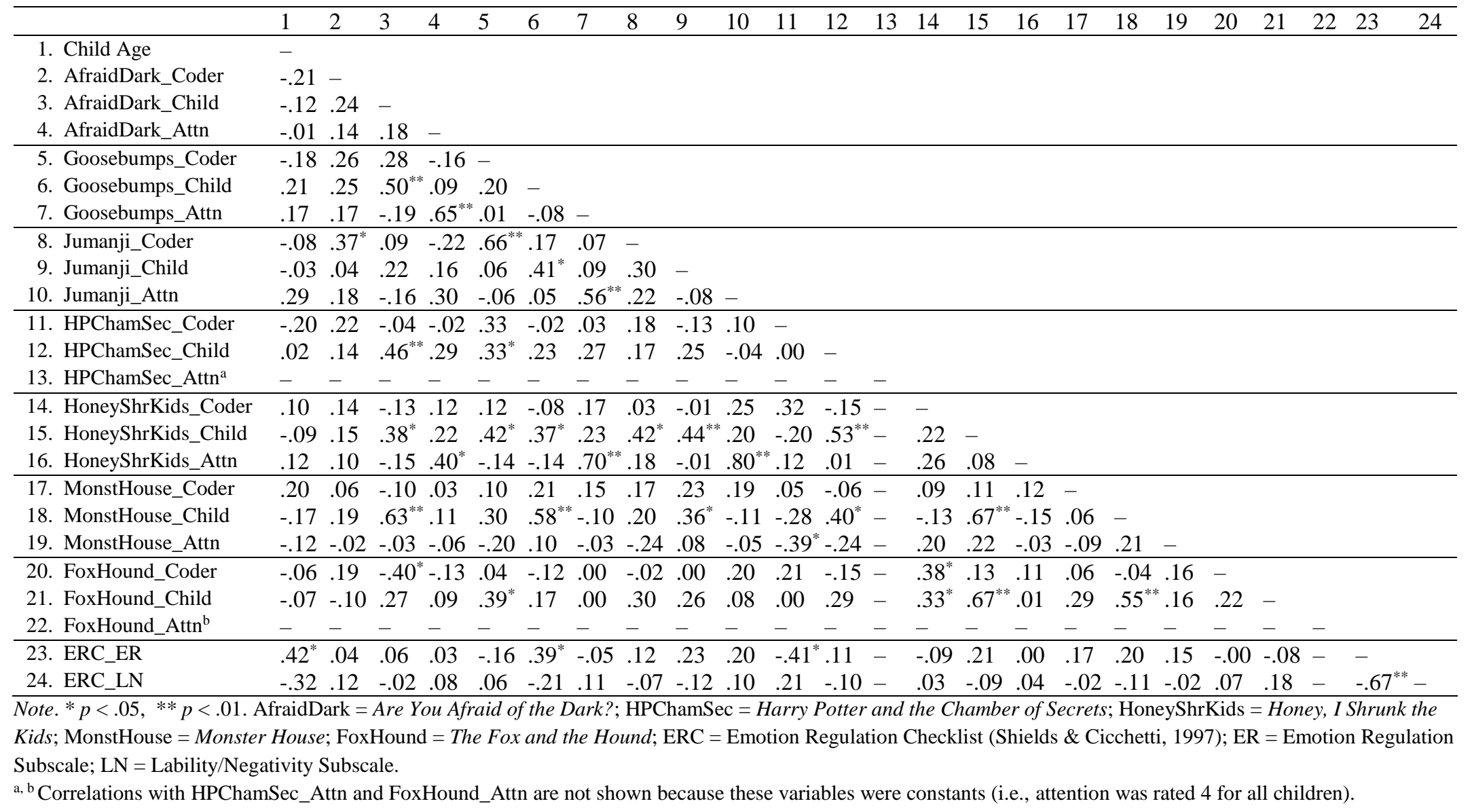


Table 8

Exploratory independent samples t-tests of sex differences in targeted emotional response, child attentiveness, and SAM valence and arousal according to coder and child ratings

\begin{tabular}{|c|c|c|c|c|c|c|c|}
\hline \multirow[b]{2}{*}{ Film Clip } & \multirow[b]{2}{*}{ Dependent Variable } & \multicolumn{2}{|c|}{ Girls } & \multicolumn{2}{|c|}{ Boys } & \multirow[b]{2}{*}{$d f$} & \multirow[b]{2}{*}{$t$} \\
\hline & & $M$ & $S D$ & $M$ & $S D$ & & \\
\hline \multicolumn{8}{|l|}{ Positive affect } \\
\hline Unaccompanied Minors & Coder-rated emotion & 2.08 & 1.07 & 1.38 & .72 & 35 & $-2.27 *$ \\
\hline Harry Potter and the Sorcerer's Stone & Child-reported emotion & 3.50 & .67 & 2.75 & 1.18 & 22.01 & $-2.28 *$ \\
\hline \multicolumn{8}{|l|}{ Sadness } \\
\hline Stepmom & Child-reported emotion & 2.42 & 1.07 & 1.56 & .73 & 33 & $-2.72 *$ \\
\hline Little Women & Child attentiveness & 3.78 & .52 & 3.25 & .86 & 22.62 & $-2.22 *$ \\
\hline \multicolumn{8}{|l|}{ Fear } \\
\hline Jumanji & Coder-rated emotion & 2.05 & .96 & 1.47 & .58 & 34 & $-2.08 *$ \\
\hline Are You Afraid of the Dark? & Coder-rated emotion & 2.12 & 1.12 & 1.50 & .45 & 26.07 & $-2.47 *$ \\
\hline Honey, I Shrunk the Kids & Child-reported emotion & 2.67 & .97 & 1.94 & 1.06 & 35 & $-2.18 *$ \\
\hline Harry Potter and the Chamber of Secrets & SAM arousal scale & 5.72 & 2.64 & 3.69 & 2.52 & 36 & $-2.40 *$ \\
\hline
\end{tabular}



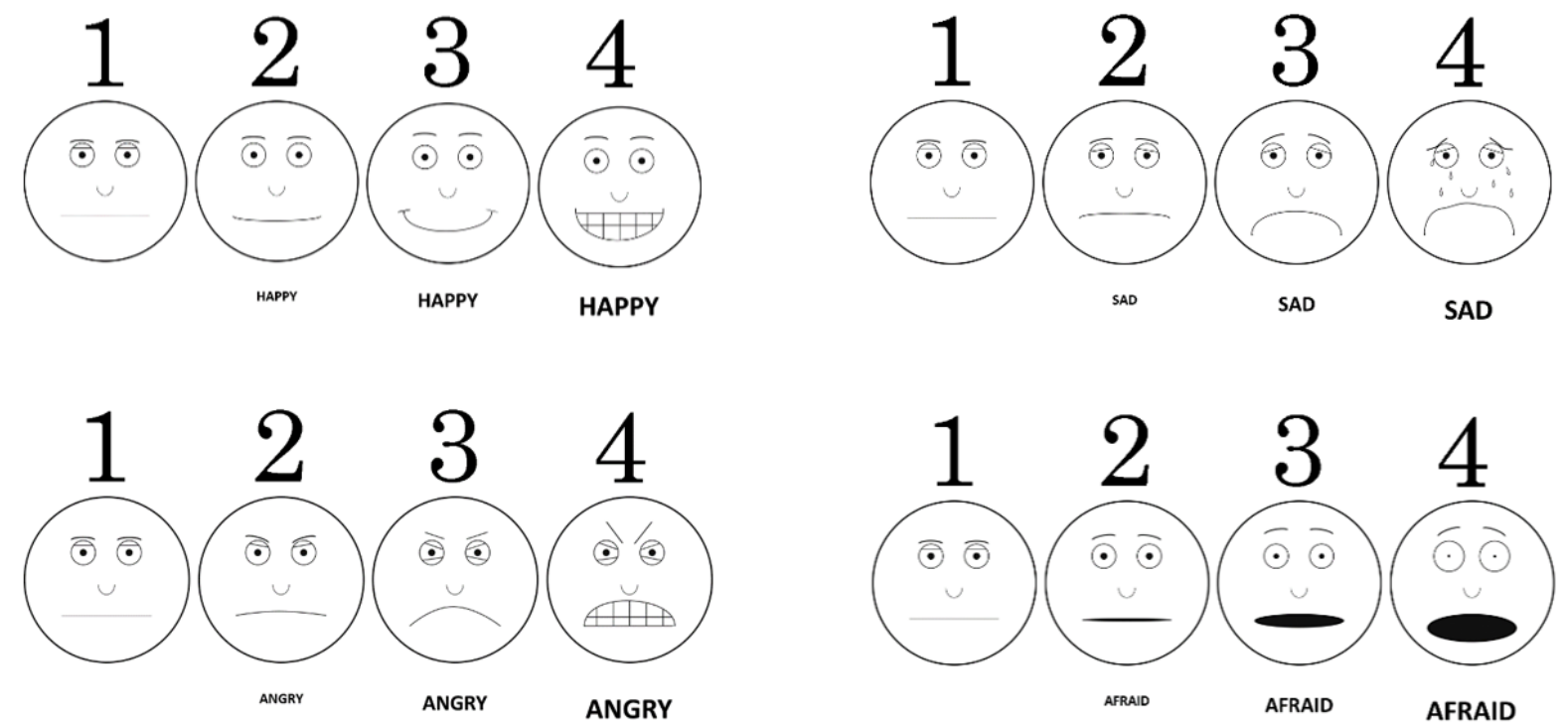

Figure 1. The child emotion self-rating scales for positive affect, sadness, fear, and anger. 


\section{Appendix A}

\section{Protocol for Introducing and Collecting Child-Reported Emotion and SAM Ratings Introduction to Rating Scales and Practice Ratings}

Instructions provided to children by research assistants during study sessions are italicized.

Today I am going to show you some short movies and I want you to tell me how each one makes you feel. We have some pictures to help you tell us how movies make you feel. A movie clip might make you feel happy [point across faces in positive affect scale], sad [point across faces in sadness scale], afraid [point across faces in fear scale], and/or angry [point across faces in anger scale]. If a movie clip made you have more than one feeling, you can pick more than one. So, you could pick a face for both angry and sad that shows those feelings if a movie clip made you feel both ways.

For practicing making ratings using the child emotion self-rating scales:

Let's practice first. Imagine I showed you a movie that made you really sad. Which face would you pick?

If it is clear that the child understands how to make ratings using these scales, it is not necessary to do a second practice rating. If the child does not appear to understand, go through a second practice rating by saying:

Now imagine I showed you a movie that made you really angry. Which face would you pick?

For practicing making ratings using the SAM valence and arousal scales:

We have another way for you to tell me how a movie made you feel. Let's look at this guy-his name is SAM [point to valence scale]. Notice that on one side, SAM is frowning [point to \#9], on the other side, SAM is smiling [point to \#1], and in the middle, SAM is not smiling or frowning [point to \#5]. These pictures are in order from a very unhappy SAM to a very happy SAM.

If you felt happy, glad, cheerful, pleased, good, or hopeful, you would pick \#1 [point to appropriate SAM], where SAM is smiling very big. If you felt unhappy, scared, angry, bad, or unhappy, you would pick \#9 [point to appropriate SAM]. If you didn't feel either happy or unhappy, then you would pick \#5 [point to appropriate SAM], where SAM is not smiling or frowning. If you felt in between being very happy and a little bit happy, you would pick \#2 [point to appropriate SAM] between pictures of SAM. 
You can use this row [point to arousal scale] to tell me how excited or calm you feel. Here you can see pictures of SAM where SAM is very still and his eyes are closed [point to \#9 SAM]. You would pick \#9 if you felt very calm, relaxed, bored, or sleepy. On this end, notice how it looks like SAM is jumping up and down and his stomach is excited [point to \#1 SAM]. This is like when you get excited and can't sit still or when you have butterflies in your stomach if you are very nervous. You would pick \#1 if you felt very excited, nervous, jittery, active, or wide awake.

\section{Collecting Ratings After Film Clip Presentations}

Repeat the following procedure for each film clip.

Following the order in which the child emotion self-rating scales are presented on the response sheet for that clip, say the following for each emotion (i.e., positive affect, sadness, fear, and anger) and point to the appropriate facial icons (1-4):

How [emotion; e.g., angry] did this movie clip make you feel? Not at all [emotion], a little [emotion], even more [emotion], or very [emotion]?

To collect the SAM valence rating, say the following:

Remember SAM? Here is SAM showing feelings ranging from very happy [point to \#1] to very unhappy [point to \#9]. Which SAM is most like how this movie clip made you feel?

To collect the SAM arousal rating, say the following:

Here is SAM feeling very excited [point to \#1] and getting calmer and calmer [point to \#9]. Which SAM is most like how this movie clip made you feel? 


\section{Appendix B}

\section{Copyright Statement}

This work contains previously published material from a journal article submitted to Psychological Assessment, a peer-reviewed journal published by the American Psychological Association. The citation for this publication is provided below. I have contacted the publisher requesting permission to allow the copyrighted material to be included in Western University's Electronic Thesis and Dissertation Repository.

Gabel, L. N., Daoust, A. R., Salisbury, M. R., Grahn, J. A., Durbin, C. E., \& Hayden, E. P. (2019, May 2). Development and validation of a battery of emotionally evocative film clips for use with young children. Psychological Assessment. Advance online publication. doi:10.1037/pas0000726 


\section{Curriculum Vitae}

$\begin{array}{ll}\text { Name: } & \text { Lindsay Gabel } \\ \begin{array}{l}\text { Post-Secondary } \\ \text { Education and } \\ \text { Degrees: }\end{array} & \begin{array}{l}\text { Western University } \\ \text { London, Ontario, Canada } \\ \text { 2017-2019, M.Sc. Candidate, Psychology }\end{array} \\ & \begin{array}{l}\text { University of Vermont } \\ \text { Burlington, Vermont, U.S.A. } \\ \text { 2009-2013, B.Sc., Psychology with Honours }\end{array} \\ & \text { Western Graduate Research Scholarship (WGRS) } \\ \text { Honours and } & \text { Western University, 2017-2019 } \\ \text { Awards: } & \text { Heinz L. Ansbacher Award for research and scholarship in } \\ & \text { psychology } \\ & \text { University of Vermont, 2013 } \\ & \text { Presidential Scholarship } \\ & \text { University of Vermont, 2009-2013 }\end{array}$

\section{Peer-Reviewed Publications:}

Gabel, L. N., Daoust, A. R., Salisbury, M. R., Grahn, J. A., Durbin, E., \& Hayden, E. P. (2019). Development and validation of a developmentally appropriate battery of emotionally evocative film clips for use with young children. Psychological Assessment. Advance online publication. doi: 10.1037/pas0000726

\section{Poster Presentations:}

1. Gabel, L. N., Daoust, A. R., Salisbury, M. R., Grahn, J. A., Durbin, E., \& Hayden, E. P. (2018, September). Development and validation of a developmentally appropriate battery of emotionally evocative film clips for use with young children. Poster presented at the 32nd annual meeting of Society for Research in Psychopathology, 2018, Indianapolis, IN, USA.

2. Gabel, L. N., \& Burt, K. B. (2013, April). Metacognitive ability as predictor of academic performance. Poster presented at the annual University of Vermont Student Research Conference, 2013, Burlington, VT, USA. 
Related Work

Experience
Graduate Teaching Assistant

Western University

2018

Graduate Research Assistant

Western University

2017-2019

Research Analyst, Mood and Anxiety Disorders Program Centre for Addiction and Mental Health (CAMH), Toronto, Ontario

2015-2017

Princeton in Asia Teaching Fellow in Psychology

Ngee Ann Polytechnic, Singapore

2013-2015 